\title{
COASTAL MODELLING WITH A GIS BATHYMETRIC MODULE
}

\section{I.K. TSANIS* \\ S. NAOUM \\ M. FULLARTON}

\author{
Department of Civil Engineering \\ McMaster University \\ 1280 Main Street West \\ Hamilton, Ontario, Canada L8S 4 L7
}

*to whom all correspondence should be addressed

e-mail: tsanis@water.eng.mcmaster.ca

tel: (905) 525 - 9140 ext 24415

\begin{abstract}
A 3D hydrodynamic/pollutant transport model was used to simulate the currents and pollutant transport in coastal areas. The bathymetric and shoreline data was provided to the model via a GIS module that operates in the ArcView GIS environment. The module is efficient and capable of generating bathymetric rectangular grids and shorelines of different resolution for open and closed boundary scenarios that can automatically be read by the coastal model. This ability could improve the basic patterns and relationships of the model such as grid dependency. The functionality of the 3D model with the GIS module is illustrated in a number of coastal areas in Greece.
\end{abstract}

KEY WORDS: ArcView GIS, Coastal Hydrodynamics, pollutant transport

\section{INTRODUCTION}

Water quality problems have been identified in many coastal areas around the world. The environmental degradation of the coastal areas has been attributed to municipal and industrial discharges. In addition to sanitary sewers and sewage treatment plant submerged discharges, a number of storm and combined sewer outfalls (CSO) and major tributaries (creeks, rivers), have significant impacts on the water quality of coastal areas. During a heavy rainfall event, the runoff from roads and buildings is collected in the combined storm and sanitary sewers where it is transported to the sewage treatment facility. If the demand on the plant is too high, the excess runoff and raw sewage in the sewers is redirected to outfalls located along the shoreline. In fact, it is not uncommon to hear of beach closures in a number of coastal areas around the world after a heavy rain event due to high pollutant levels. Significant reductions can be made to the pollutant levels if the redirected flow is restricted from discharging directly into the coast. For example, by collecting the overflow in large underground storage containers, the level of pollutants usually contributed by the sewers is reduced to zero (Tsanis, 1996). Other potential options include separating the remaining combined systems, or decentralizing the collection and treatment of combined sewage and storm water by adding more, smaller treatment facilities.

Geographic Information Systems linked with different environmental simulation models can provide functions for data storage, calculation of 
required input parameters, data manipulation, and output processing (Maidment, 1993; Tsanis et al., 1996; Goodchild et al., 1995; Naranjo and Larsen, 1998; Lichy, 1998). GIS technology is also central to these models by providing the system with spatial data management, analysis, display and interface functions (Boyle et al., 1998; Boyle and Tsanis, 1998). Hydrodynamic/pollutant transport modelling requires functions for data input, processing, and output of spatially distributed information. There are many means to provide this functionality, for example closed-coupled GIS models such as the IDOR2D (Tsanis and Boyle, 2001) and loose-coupled GIS model (Naoum et al., 2002).

In this paper, a GIS interface operating in the ArcView GIS environment was used to provide the bathymetic grid and shoreline needed for the 3D hydrodynamic/pollutant transport model IDOR3D, which is a DOS-based educational and research program developed at McMaster University, in order to simulate the currents and pollutant transport in a number of coastal areas in Greece. The remainder of the paper is organized as follows: Section 2 provides the description of the 3D hydrodynamic/pollutant transport model. In section 3 the use of the GIS module in the hydrodynamic modelling is described. Section 4 describes the case study. In section 5 the modelling results are reported and discussed; and finally, section 6 concludes the presentation.

\section{METHODOLOGY}

\section{Governing Equations}

Three-dimensional governing equations for windinduced circulation in coastal areas were derived from the Navier-Stokes equations by using the following assumptions:

- Shallow water assumption: the vertical accelerations are small enough to be ignored, which results to the hydrostatic pressure distribution

- Boussinesq approximation: the variation of water density is taken into account only in the gravity term.

$$
\frac{\partial u}{\partial x}+\frac{\partial v}{\partial y}+\frac{\partial w}{\partial z}=0
$$

$$
\begin{aligned}
& \frac{\partial u}{\partial t}+\frac{\partial(u u)}{\partial x}+\frac{\partial(v u)}{\partial y}+\frac{\partial(w u)}{\partial z}= \\
& =f v-\frac{1}{\rho_{0}} \frac{\partial p}{\partial x}+v_{h} \frac{\partial^{2} u}{\partial x^{2}}+v_{h} \frac{\partial^{2} u}{\partial y^{2}}+\frac{\partial}{\partial z}\left(v_{v} \frac{\partial u}{\partial z}\right)
\end{aligned}
$$

$$
\begin{aligned}
& \frac{\partial v}{\partial t}+\frac{\partial(u v)}{\partial x}+\frac{\partial(v v)}{\partial y}+\frac{\partial(w v)}{\partial z}= \\
& =-f u-\frac{1}{\rho_{0}} \frac{\partial p}{\partial y}+v_{h} \frac{\partial^{2} v}{\partial x^{2}}+v_{h} \frac{\partial^{2} v}{\partial y^{2}}+\frac{\partial}{\partial z}\left(v_{v} \frac{\partial v}{\partial z}\right)
\end{aligned}
$$

$$
0=-g-\frac{1}{\rho} \frac{\partial p}{\partial z}
$$

$$
\begin{aligned}
& \frac{\partial T}{\partial t}+\frac{\partial(u T)}{\partial x}+\frac{\partial(v T)}{\partial y}+\frac{\partial(w T)}{\partial z}= \\
& =S_{T}+K_{h} \frac{\partial^{2} T}{\partial x^{2}}+K_{h} \frac{\partial^{2} T}{\partial y^{2}}+\frac{\partial}{\partial z}\left(K_{v} \frac{\partial T}{\partial z}\right) \\
& \frac{\partial C}{\partial t}+\frac{\partial(u C)}{\partial x}+\frac{\partial(v C)}{\partial y}+\frac{\partial(w C)}{\partial z}= \\
& =S_{C}+M_{h} \frac{\partial^{2} C}{\partial x^{2}}+M_{h} \frac{\partial^{2} C}{\partial y^{2}}+\frac{\partial}{\partial z}\left(M_{v} \frac{\partial C}{\partial z}\right)
\end{aligned}
$$

where: $\mathrm{u}, \mathrm{v}$, and $\mathrm{w}$ are the velocity components in the $\mathrm{x}, \mathrm{y}$, and $\mathrm{z}$ directions, with $\mathrm{x}$ positive eastward, $\mathrm{y}$ positive northward, and $\mathrm{z}$ positive upward; $\mathrm{f}$ is the Coriolis parameter; $p$ is the water pressure; $g$ is the acceleration due to gravity; $\varrho$ is the water density; $\varrho_{0}$ is the reference water density (at $4^{\circ} \mathrm{C}$ ); $\mathrm{T}$ is the water temperature; $v_{\mathrm{h}}$ and $v_{\mathrm{v}}$ are the eddy viscosity coefficients in the horizontal and vertical directions, respectively; $\mathrm{S}_{\mathrm{T}}$ is the source term for the water temperature; $\mathrm{K}_{\mathrm{h}}$ and $\mathrm{K}_{\mathrm{v}}$ are the eddy diffusivity coefficients for water temperature in the horizontal and vertical directions, respectively; $\mathrm{C}$ is the concentration; $\mathrm{S}_{\mathrm{C}}$ is the source for concentration; and $\mathrm{M}_{\mathrm{h}}$ and $\mathrm{M}_{\mathrm{v}}$ are the eddy diffusivity coefficients in the horizontal and vertical directions, respectively. Finally the equation of state $\varrho=\varrho(T, S)$, where $S$ is the salinity, provides the link between density and temperature. 


\section{Boundary Conditions}

At the water surface $(z=\xi)$, the kinematic condition can be derived:

$w_{s}=\frac{\partial \varsigma}{\partial t}+u_{s} \frac{\partial \varsigma}{\partial x}+v_{s} \frac{\partial \varsigma}{\partial y}$

where: subscript $\mathrm{s}$ denotes the variables at the water surface. The wind shear stresses can be connected to the boundary conditions as follows:

$$
\begin{aligned}
& \left(\tau_{s x}, \tau_{s y}\right)=\left.\rho_{a} v_{v}\left(\frac{\partial u}{\partial z}, \frac{\partial v}{\partial z}\right)\right|_{z=\varsigma}= \\
& =C_{s} \rho_{a}\left(W_{x}, W_{y}\right) \sqrt{W_{x}^{2}+W_{y}^{2}}
\end{aligned}
$$

where: $\mathrm{W}$ is the wind speed; $\varrho_{\mathrm{a}}$ is the air density and; $\tau_{\mathrm{s}}$ is the wind shear stress; $\mathrm{C}_{\mathrm{s}}$ is the wind shear stress coefficient. This model can incorporate the heat exchange at the water surface, but it is assumed that there is no heat exchange at the water surface in this study. No flux of concentration at the water surface is considered.

At the sea bottom $\left(z=z_{b}\right)$, the following kinematic condition is obtained:

$$
w_{b}=u_{b} \frac{\partial z_{b}}{\partial x}+v_{b} \frac{\partial z_{b}}{\partial y}
$$

where: subscript $\mathrm{b}$ expresses the variables just above the bottom boundary layer. The bottom shear stresses are given as:

$$
\begin{aligned}
& \left(\tau_{b x}, \tau_{b y}\right)=\left.\rho_{0} v_{v}\left(\frac{\partial u}{\partial z}, \frac{\partial v}{\partial z}\right)\right|_{z=z_{b}}= \\
& =C_{b} \rho_{0}\left(u_{b}, v_{b}\right) \sqrt{u_{b}^{2}+v_{b}^{2}}
\end{aligned}
$$

where: $\tau_{b}$ is the bottom shear stress and $C_{b}$ is the bottom drag coefficient. No heat and concentration fluxes through the sea bottom are considered.

At the shore, the components of velocity perpendicular to the shore, and the heat and conductivity fluxes through the shore are assumed to be zero. Where the shore has inflow or outflow rivers, the velocity components normal to the shore are considered to be equal to the velocities of the inflow or outflow rivers, and the heat and concentration exchanges are expressed by:

$u_{n} T-K_{h} \frac{\partial T}{\partial n}=u_{r} T_{r}$

$$
u_{n} C-M_{h} \frac{\partial C}{\partial n}=u_{r} C_{r}
$$

where: subscript $\mathrm{n}$ is the normal direction to the shore; $u_{r}, T_{r}$, and $C_{r}$ are the velocity, temperature and concentration of the inflow or outflow rivers, respectively.

At the open boundaries, the velocity and water elevation at the open boundaries must be specified. When the data of the velocity and water elevation at the open boundaries are not available, the following free radiation open boundary conditions are used.

Water elevation: $\frac{\partial \zeta}{\partial n}=0$

Tangential velocity component:

$\frac{\partial v_{t}}{\partial t}+\frac{\partial}{\partial n} v_{n} v_{t}=0$

Normal velocity component: $\frac{\partial u_{n}}{\partial n}=0$

where: subscripts $\mathrm{n}$ and $\mathrm{t}$ are the normal and tangential directions to the open boundary, respectively.

The Reynolds stress terms should be specified in order to solve the equations of motion. Tsanis (1989) compared different turbulence models and concluded that the mixing length model (Reid, 1957), the $x-\varepsilon$ model (Svensson, 1978) and the eddy viscosity model (Pearce and Cooper, 1981) had very similar vertical current structures. In this paper, because the eddy viscosity model proposed by Pearce and Cooper is much simpler than the others, it is used for the vertical eddy viscosity. That is, the vertical eddy viscosity coefficient was taken as zero at the water surface, increasing linearly to 1 
metre depth from the surface, and constant from that depth until the bottom. This constant eddy viscosity is calculated by $\left(v_{v} \approx 0.08 \mathrm{u}_{*_{\mathrm{S}}} \mathrm{H}\right)$, in which " $\mathrm{u}_{*_{\mathrm{S}}}$ " is the shear velocity at the water surface and " $\mathrm{H}$ " is the water depth. In stratified cases, the eddy viscosity and diffusivity are reduced by the stable stratification and often evaluated by the following formulas (Leendertse and Liu, 1975),

$\nu_{v}=\nu_{v 0} e^{-1.5 R i} K_{v}=K_{v 0} e^{-3.0 R i} M_{v}=M_{v 0} e^{-3.0 R i}(16)$

where: $\mathrm{v}_{0}, \mathrm{~K}_{\mathrm{v} 0}$ and $\mathrm{M}_{\mathrm{v} 0}$ are the eddy viscosity and diffusivities in the neutral state (isothermal state) respectively, $\mathrm{Ri}$ is the local Richardson number and is defined as:

$$
R i=\frac{g \partial T / \partial z}{\rho_{0}(\partial \bar{u} / \partial z)^{2}}
$$

in which: $\mathrm{u}$ is the average velocity in the horizontal plane. A large Richardson number implies that the stratification is strong and thus the vertical transports of momentum and pollutant are more suppressed. If the Richardson number is negative, turbulence is stimulated and strengthens by the buoyancy force and the kinetic energy of turbulence will increase. As a result, the vertical transports of momentum and pollutant will be more intensive than in the neutral state. In the model, it is assumed that instantaneous mixing happens when the Richardson number is negative. This model can incorporate spatially variable horizontal eddy viscosity $v_{h}$, however $v_{h}$ was calculated by: $v_{\mathrm{h}}=10^{-3} \Delta_{\mathrm{h}}^{4 / 3}\left(\mathrm{~m}^{2} \mathrm{~s}^{-1}\right)$ for this study, in which $\Delta_{\mathrm{h}}$ is the grid size (m) in the horizontal plane.

\section{Numerical Analysis Techniques}

Many numerical schemes have been presented for discretizing the governing equations. Most of the numerical schemes are conditionally stable, that is, the time steps are restricted by several stability conditions. The time step is limited by the Courant-Friedrichs-Levy (CFL) condition if the barotropic pressure is discretized by an explicit scheme,

$$
\sqrt{g H_{\max }} \Delta t \sqrt{\frac{1}{\Delta x^{2}}+\frac{1}{\Delta y^{2}}+\frac{1}{\Delta z^{2}}} \leq 1
$$

where: " $\mathrm{H}_{\max }$ " is the maximal water depth and " $\Delta \mathrm{x}, \Delta \mathrm{y}$, and $\Delta \mathrm{z}$ " are the grid lengths in the " $\mathrm{x}, \mathrm{y}$, and $z$ " directions respectively. The other stability conditions are imposed by the diffusion

$v_{h} \Delta t\left(\frac{1}{\Delta x^{2}}+\frac{1}{\Delta y^{2}}\right)+\frac{v_{v} \Delta t}{\Delta z^{2}} \leq 1 / 2$

and Coriolis term: $\Delta t<\frac{1}{f}$

Among these stability conditions, the CFL condition is the most stringent. If the CFL condition is not imposed, a much larger time step can be chosen.

The governing equations were approximated by the control volume method on the Arakawa-C staggered grid (Arakawa, 1966). A semi-implicit difference scheme was used for the barotropic pressure, known as the SIMPLER (Semi-Implicit Method for Pressure-Link Equation Revised) method (Patankar, 1980). This method results in a Poisson equation of the water elevation, which was solved by the SOR (Successive OverRelaxation) method (Roache, 1972). In the SIMPLER method, the time step is not limited by the CFL condition and thus a larger time step can be chosen to save CPU time. The Adams-Bashforth scheme was used for the temporal terms and the weight averaged Donor-cell scheme for the advective terms. Although the Adams-Bashforth scheme has been proven by the Neumann's stability analysis to exhibit weak dispersion when only advective terms exist, this scheme is stable if diffusive terms are involved (Roache, 1972). The Adams-Bashforth scheme is second-order accurate in time, and requires values at only two time increments. The Donor-cell scheme is a secondorder upstream scheme in space and avoids numerical stability problems caused by the nonlinear advective terms (Roache, 1972). The central difference scheme of second order accuracy in space was used for the diffusive term. As a result, the numerical model is second-order accurate in both time and space. The above-described model is called IDOR3D. The procedure of calculation has the following steps:

- The advective terms, diffusive terms, Coriolis terms and the components of pressure terms 
are not related to the water surface elevation $\xi^{n+1}$, are calculated from the hydraulic quantities of time $\mathrm{n} \Delta \mathrm{t}$. Time is determined by the number of time steps $\mathrm{n} \Delta \mathrm{t}$ from the reference time, with $\mathrm{n}$ as an integer value.

- The water surface elevation $\zeta^{n+1}$ is calculated by the Successive Over Relaxation (SOR) method from the Poisson equation, and $\Delta \mathrm{z}^{\mathrm{n}+1}$ can be obtained from $\zeta^{n+1}$.

- The velocity $\mathrm{u}^{\mathrm{n}+1}$ and $\mathrm{v}^{\mathrm{n}+1}$ are calculated from the momentum equations.

- The vertical velocity $\mathrm{w}^{\mathrm{n}+1}$ is calculated by substituting the obtained velocities $\mathrm{u}^{\mathrm{n}+1}$ and $\mathrm{v}^{\mathrm{n}+1}$ into the continuity equation.

- The temperature $\mathrm{T}$ is calculated from the temperature equation and the density @ is calculated from the relationship between temperature and density.

- The concentration $\mathrm{C}$ is calculated from the transport equation.

\section{THE GIS ROLE IN 3D HYDRODYNAMIC MODELING}

A GIS module was used in this paper to prepare input ASCII files representing the bathymetric grid and shoreline necessary for running the hydrodynamic/pollutant transport model. Digital hydrographic files normally represent the definition of the bathymetry of the computational domain. Since the hydrographic files were in decimal degrees (geographic projection), projecting them in the appropriate projection is the first step in order to properly link all bays and any additional information. Upon completing projection, the files were converted to ArcView shapefiles; filtered to eliminate any irrelevant information for this specific application (i.e. rivers); edited to fix any errors and erase any unnecessary features (i.e. moving any spot depths points to be inside the shoreline, trim shoreline, ...etc); and manipulated to match the desired features by the module to generate grids (i.e. convert contours to points, convert shoreline from polygon to polyline, merge islands and shoreline, ...etc).

The written scripts are then run consecutively to perform the grid generation, which also have been designed to prompt the user with some dialogs and messages for guidance and interaction. The depth grids may be defined for either a sub-area or the full extent of the available input data. The depth grids can also be generated for open or closed boundary conditions as will be seen in the following sections. The automatic, quick, and accurate generation of depth grids, accompanied by the visual capability of ArcView, provides the means for studying the impact of grid-resolution on the 3D Hydrodynamic/Pollutant Transport model outputs. The user can specify both the grid cell size and the interpolation technique.

After collecting all necessary information from the user through prompts and messages, the program starts executing the task of generating the depth grid. The execution time depends exclusively on the interpolation technique, the size of the bay, and the cell size. The user is then informed of the completion of the operation by displaying a message on the screen. The ASCII file is then generated together with a visual presentation of the grid. Finally, another process is initiated by running a series of ArcView scripts that convert the shoreline (including islands if they exist) to points separated at user-specified spacing. The text file is then generated.

The hydrodynamic model IDOR3D requires additional processing of files once the shore and bathymetric files have been generated. The following steps are necessary for running the IDOR3D model

(a) The bottom topography of the computational domain must be defined. The depths of the domain are interpolated from the topography file, created by ArcView GIS and an additional program runs to generate a depth grid.

(b) Generation of two files that contain information about each grid (column) within the larger grid system. The depths in each column are expressed as cells. The number of cells in a column is directly related to the depth of water at that point, and the number of layers defined in a file, which specifies the thickness of each layer.

(c) To define the simulation, IDOR3D reads two 


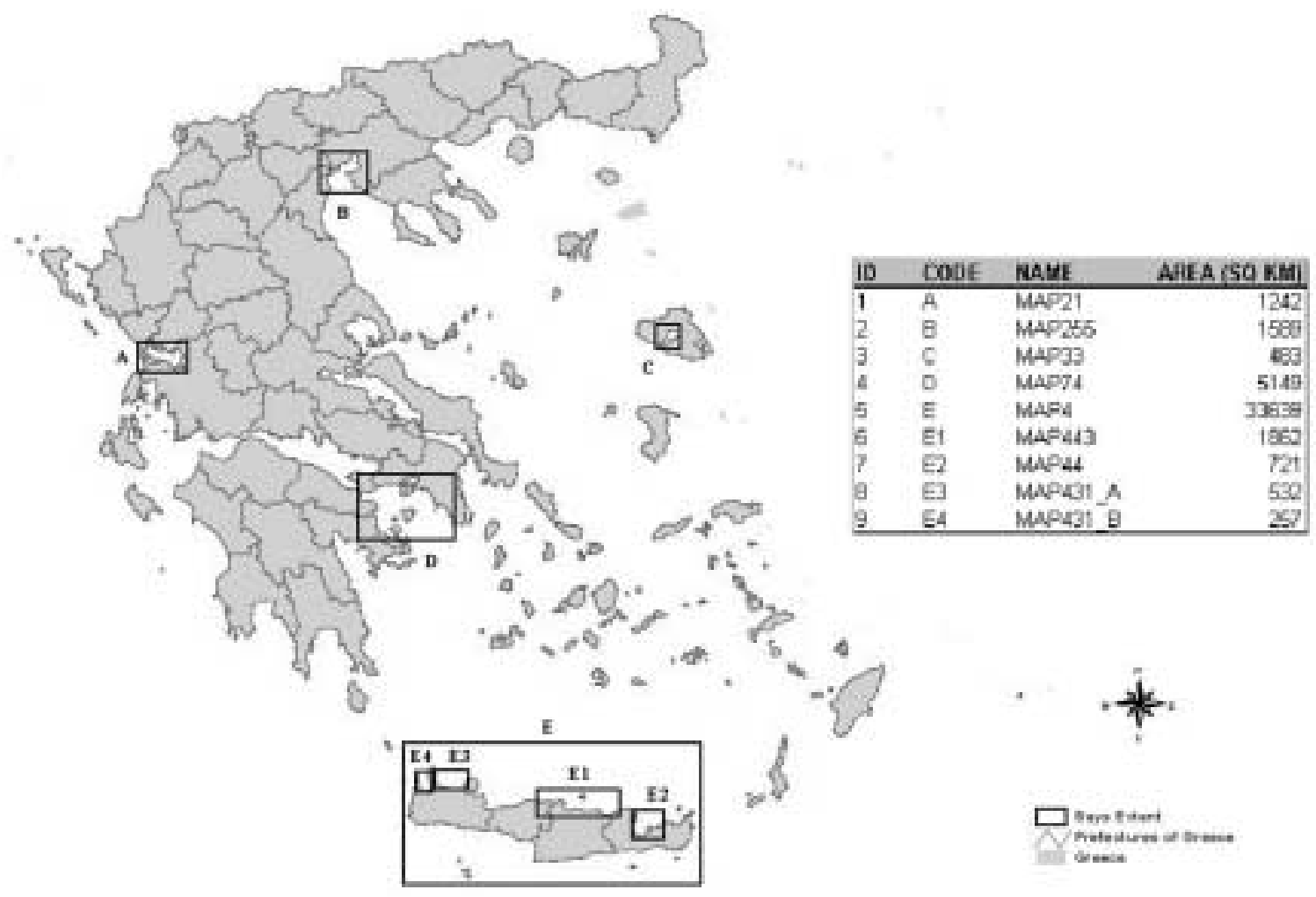

Figure 1. Selected bays in the country of Greece

0 300 Filometers

parameter files. The first file provides IDOR3D with information such as simulation length, date and time of simulation, time series locations, time levels when variables about the whole water body are to be saved, as well as wind and source characteristics. The second file defines the physical characteristics of the body of water provided by experts such as diffusivity, viscosity, water density, drag coefficient, etc.

\section{CASE STUDY}

Selected coastal areas in Greece, as shown in Figure 1, were chosen as test cases to illustrate the functionality of coupling the 3D model with the GIS module. In addition to the availability of the data, the coastal areas were selected to reflect: a) different boundary conditions, b) various sizes (areas), and c) different locations around the country. The data was obtained from hydrographic files which, mostly, included information on spot depths, bathymetric contours, shorelines, islands, and rivers. Figure 2 shows an example of a hydrographic file for the
Thessaloniki bay (map section B), which was processed through the GIS module to a proper format for generating the bathymetric file. Additional bathymetric information was available for the island of Crete (which is located to the far south of Greece) and five areas were selected that represent: (a) area E, the coast of the whole island; and (b) four coastal areas in the north shore of Crete. These cases were run for the island employing different modeling scenarios that include one, two, three, and four open boundaries. Additional information from the Digital Elevation Model (DEM) of the island can provide information, as shown in Figure 3, of point sources discharging in the near shore of the island. For complicated shorelines, small cell sizes are generally preferred in order for the grid to conform to the shore. Figure 4a shows a $1000 \mathrm{~m}$-grid for the Amvrakikos bay (map section A), while Figure $4 \mathrm{~b}$ shows a $50 \mathrm{~m}$-grid for the same area. Notice the difference for the northwest part of the bay, which is enlarged on both figures in the insets. 


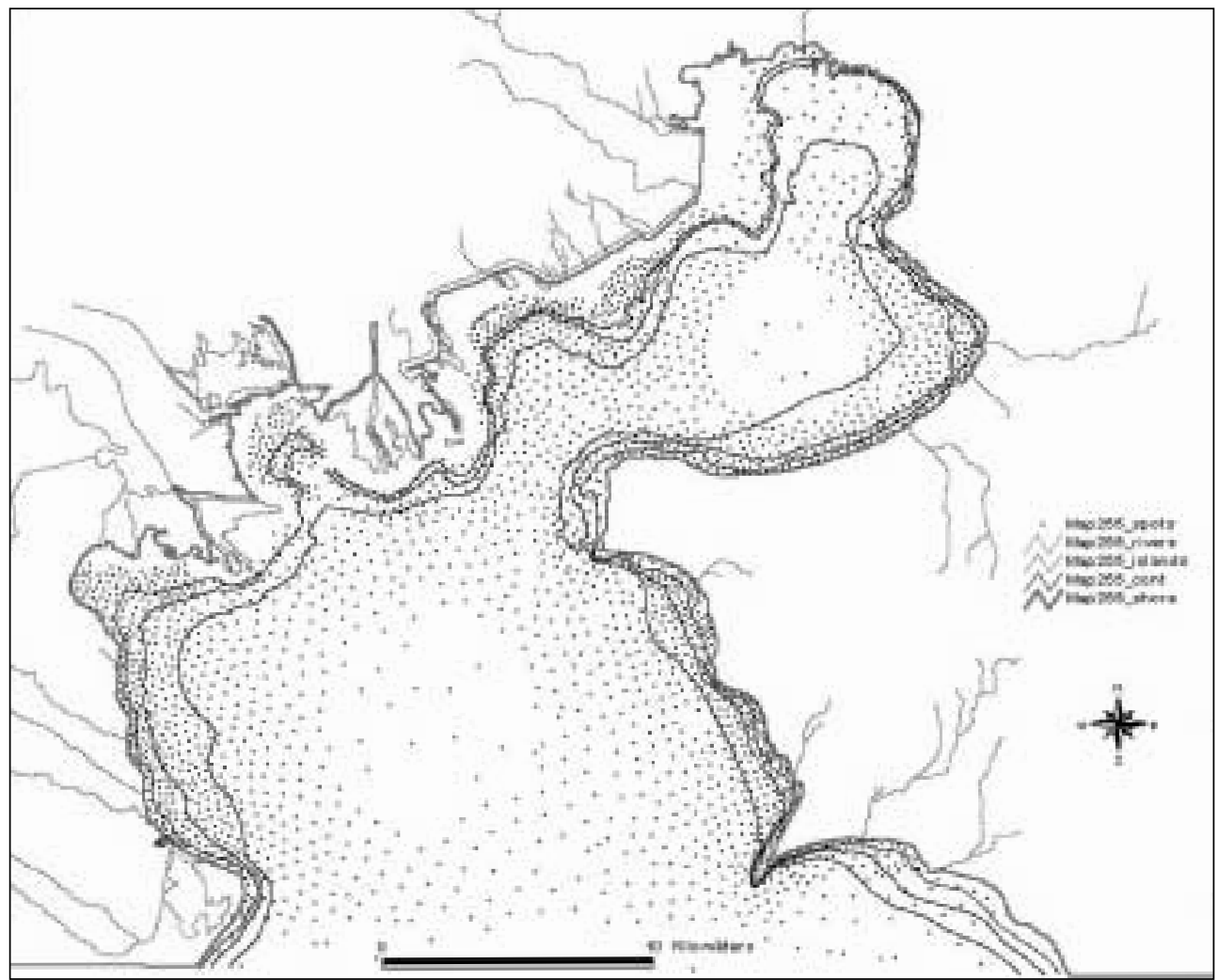

Figure 2. A hydrographic file for the Thessaloniki bay

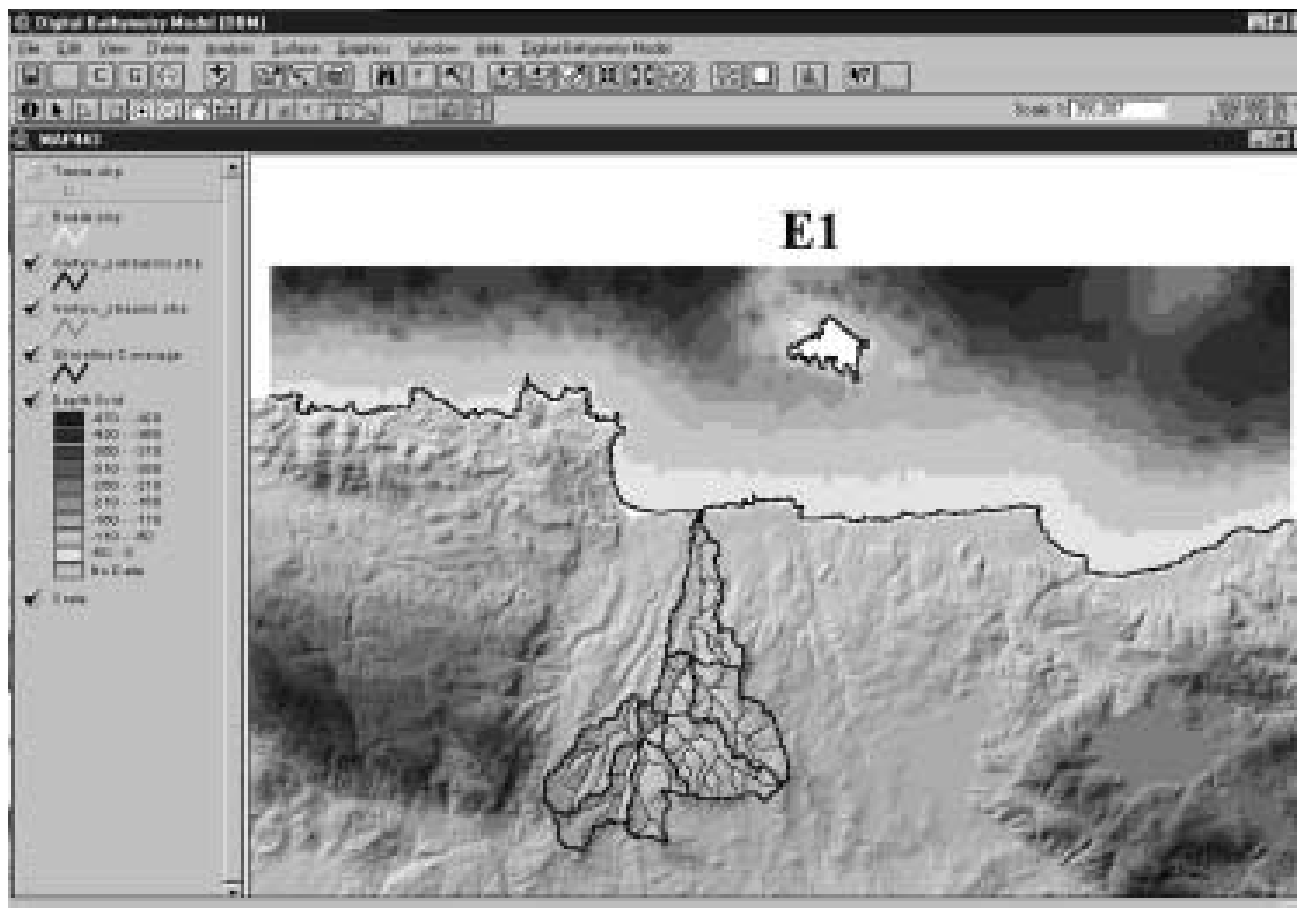

Figure 3. A digital bathymetry model (DBM) together with a digital elevation model (DEM) for the north shore of the Iraklion prefecture 


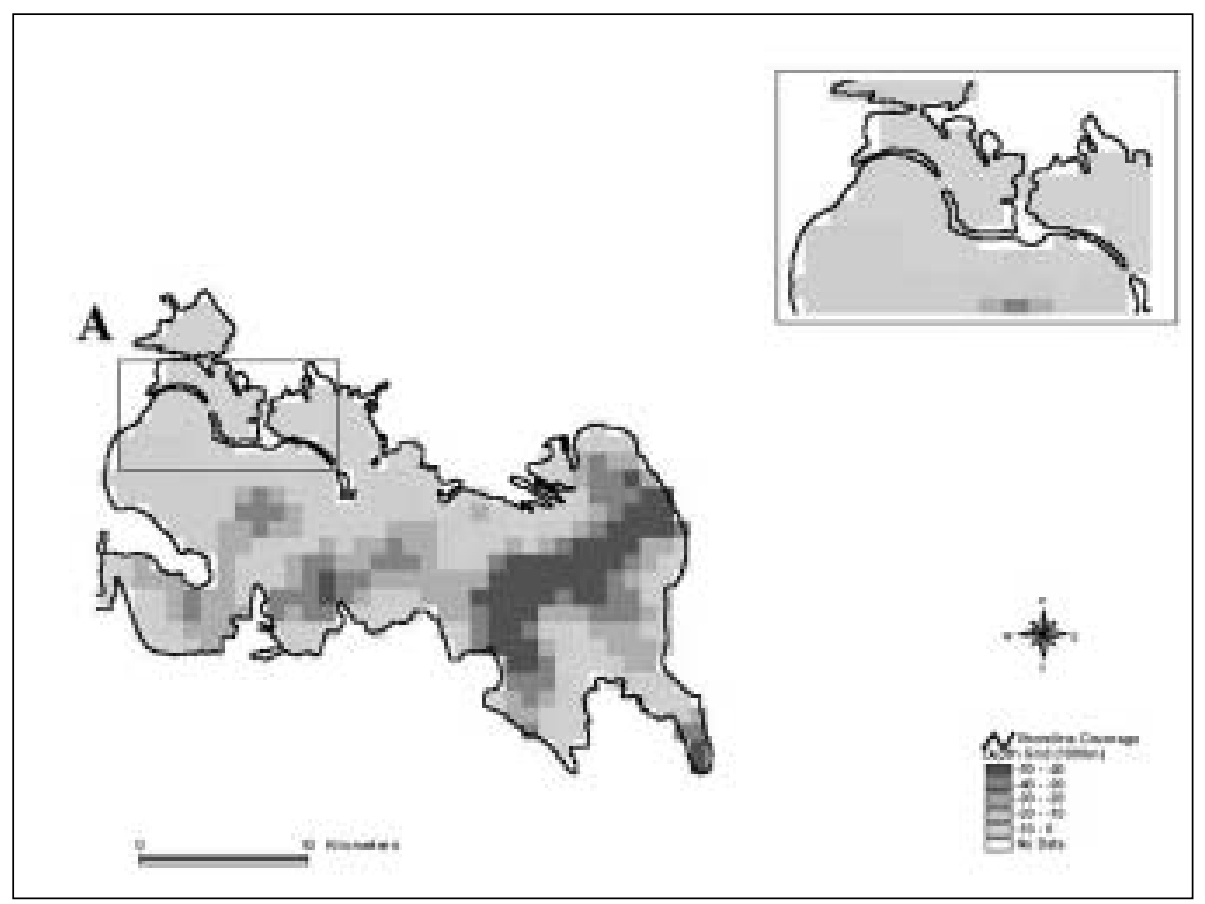

Figure 4a. A 1000m-grid for the Amvrakikos bay

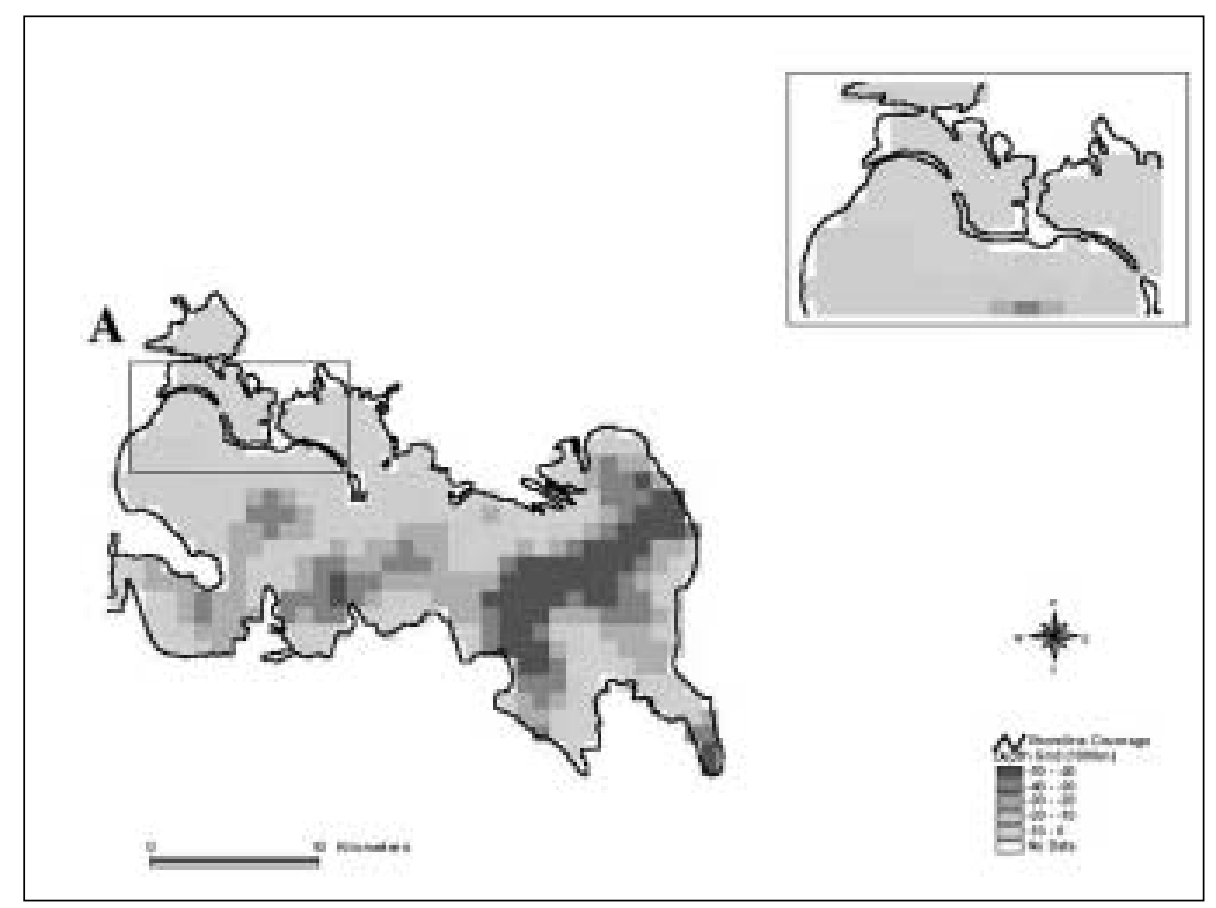

Figure 4b. A 50m-grid for the Amvrakikos bay 


\section{RESULTS AND DISCUSSION}

A number of simulations were performed on various bays in Greece. Figure 5 shows the current distribution at the surface and at a depth of $20 \mathrm{~m}$ based on a $5 \mathrm{~m} \mathrm{~s}^{-1} \mathrm{NW}$ wind in Thessaloniki bay (map section B) located in north Greece. The wind-induced currents pro- duce a consistent flow pattern at the surface and generate a return flow at a depth of $20 \mathrm{~m}$. Figure 6 examines the surface layer current patterns for Kalloni bay (map section C) under a constant $5 \mathrm{~m} \mathrm{~s}^{-1}$ wind applied from the SW and the NW. Eddy currents form at the surface under both wind conditions as a result of the
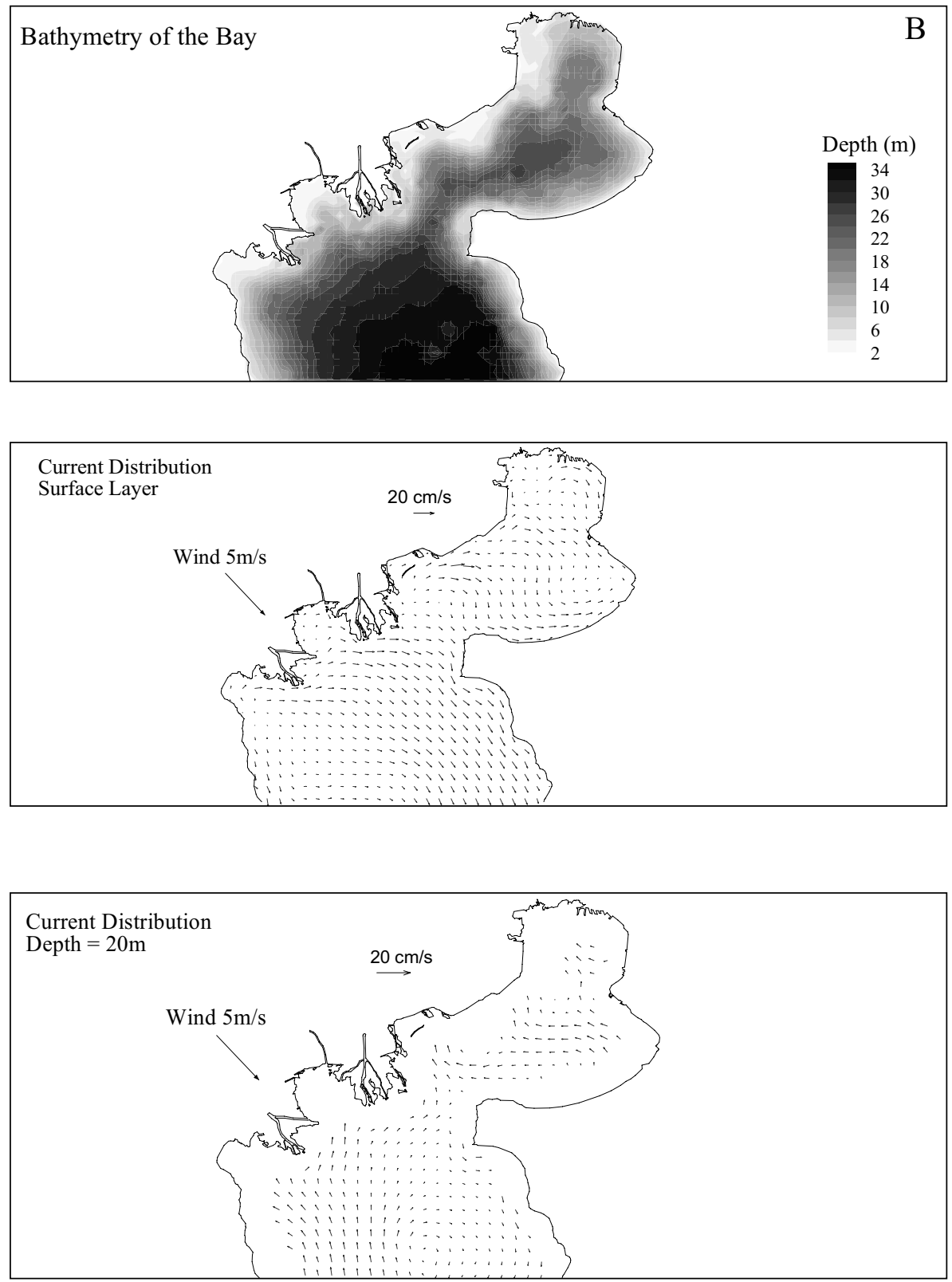

Figure 5. Shows the bathymetry of Thessaloniki bay (Section B) and the current distribution at the surface and at a depth $=20 \mathrm{~m}$ based on a NW wind $=5 \mathrm{~m} \mathrm{~s}^{-1}$. 
geometry of the bay, which is long and narrow. Figure 7 illustrates the bathymetry and surface layer flow distribution under a constant $5 \mathrm{~m} \mathrm{~s}^{-1}$ NW wind for the Saronikos bay near Athens (map section D). The uniform depth averaged current patterns are represented in Figure 7 along with referenced depth averaged flow for the NE corner of the bay. A number of eddy currents are prevalent within the extent of the domain due to the presence of islands, small inlets and the bathymetry of the bay.

As previously mentioned and due to the availability of additional bathymetric data for the island of Crete, five runs, employing different boundary and pollutant source conditions, were performed for the island in the areas shown in
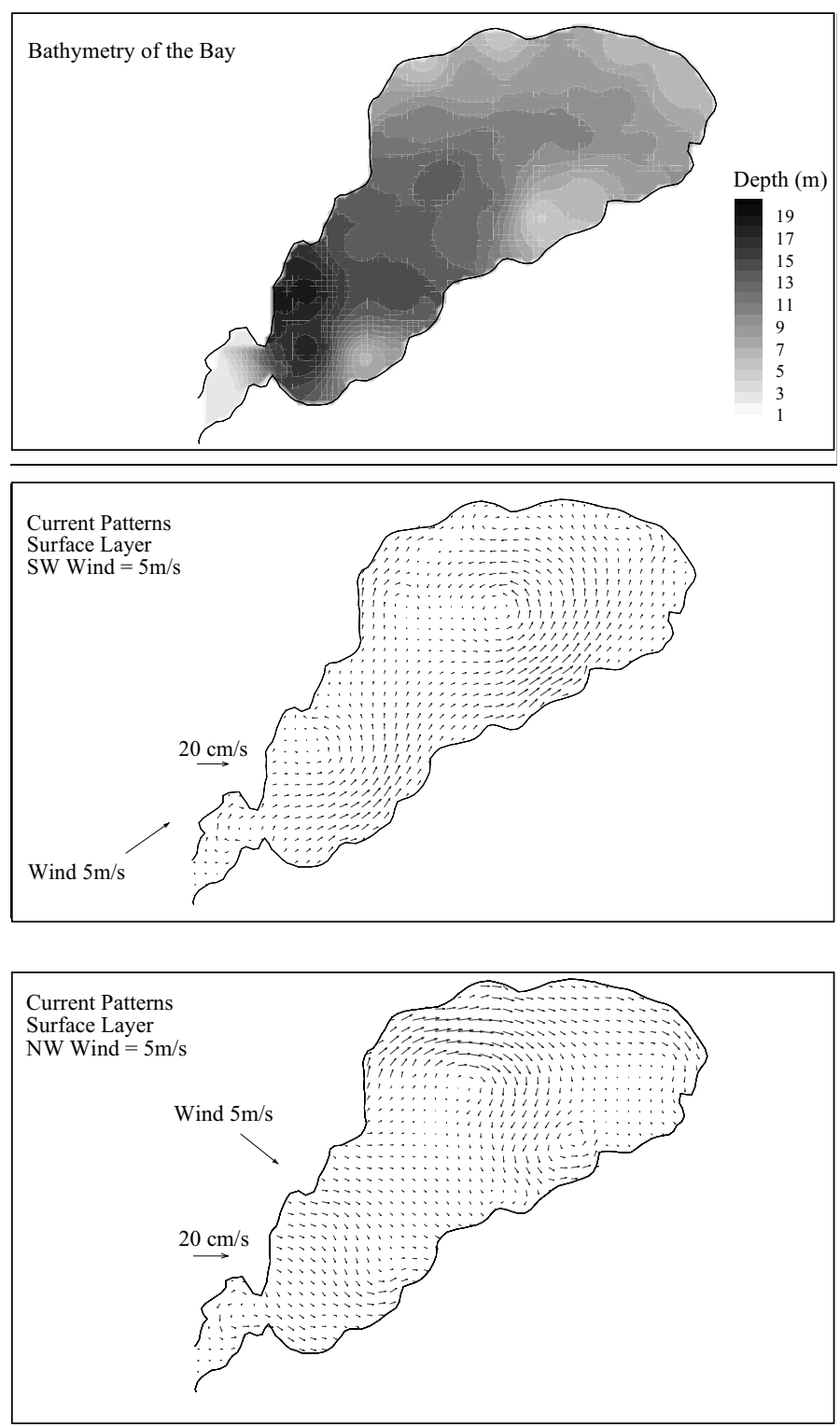

Figure 6. Shows the bathymetry of Kalloni bay (Section C) and the current distribution based on a $5 \mathrm{~m} \mathrm{~s}^{-1} \mathrm{SW}$ and NW wind direction. 

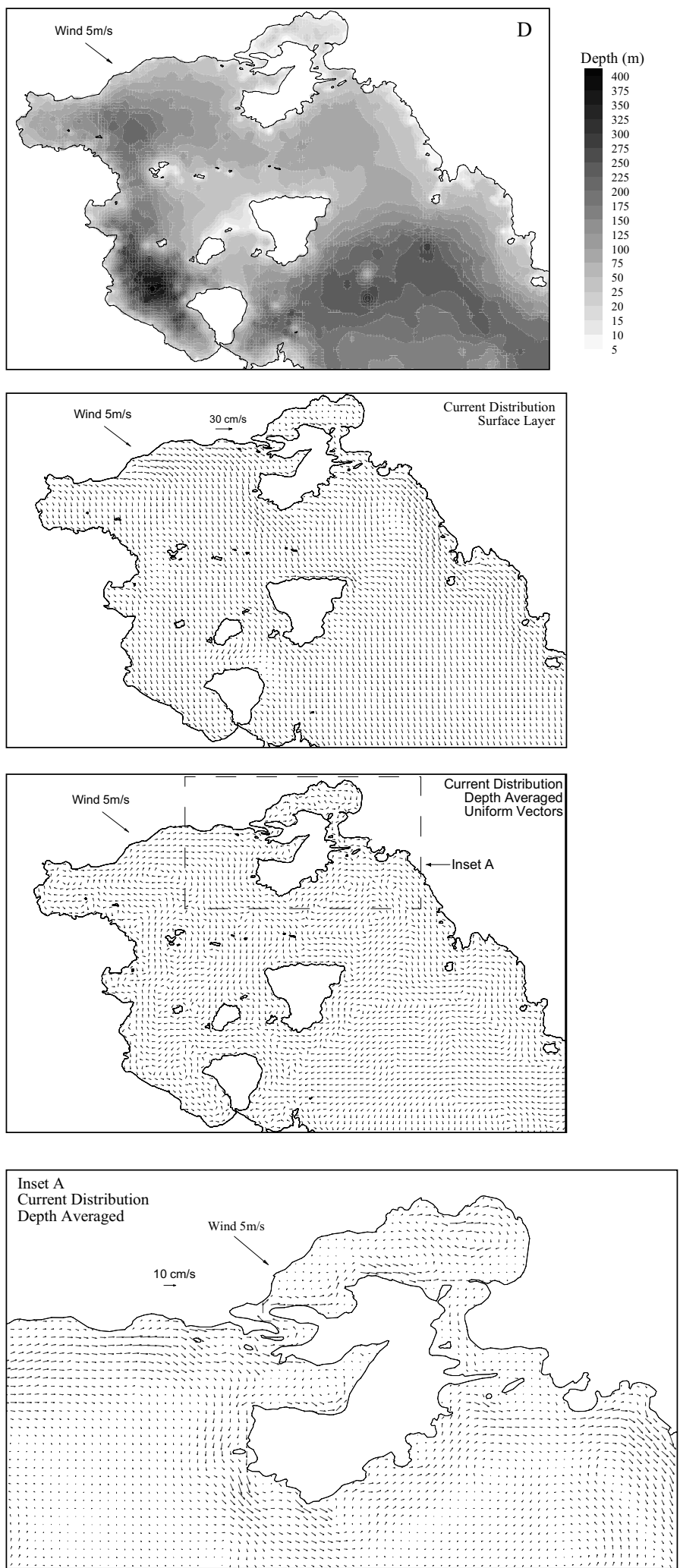

Figure 7. Shows the bathymetry of Saronikos bay (Section D) the surface layer current patterns for a $5 \mathrm{~m} \mathrm{~s}^{-1}$ NW wind. It also describes the depth averaged current patterns for Saronikos bay (Section D) using uniform vectors for the entire bay and actual magnitude vectors for the NE corner of the bay. 

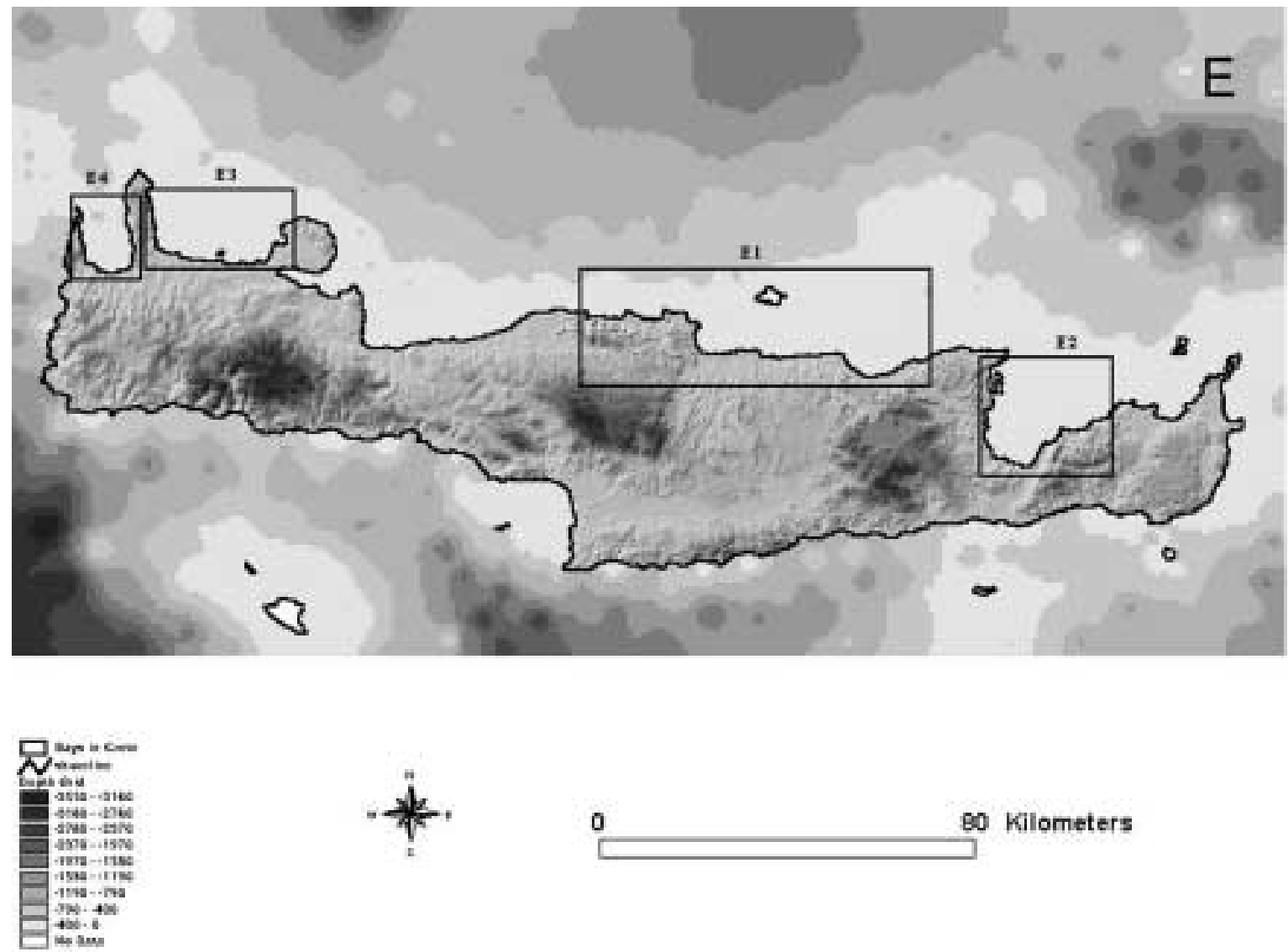

0

Figure 8. The DBM and DEM of the island of Crete and its selected bays

Figure 8. The distribution of the surface layer currents around the Island of Crete (map section E) under a NW wind is illustrated in Figure 9. A section along the north shore of the island (north of the Iraklion prefecture) was also considered in order to simulate the surface flow based on a NW and NE wind. Figure 10 describes the bathymetry and current patterns at the surface and at a depth of $200 \mathrm{~m}$ for Agios Nikolaos bay based on a NW wind. As expected the currents at the surface are driven by the wind and a return flow is prevalent at a depth of $200 \mathrm{~m}$ following the bottom topography of the bay.

The two bays located along the north shore of Chania region were used to examine the hydrodynamics and pollutant transport of a hypothetical contaminant discharged under various conditions. Kasteli bay (map section E4) was used to simulate the fate of a pollutant discharged over a four-hour period. Chania bay (map section E3) was used to examine the transport of a pollutant discharged continuously from a source for the entire simulation from two different locations. The first scenario to consider involves Kasteli bay. As shown in Figure 11, a watershed is discharging through two streams into the bay, which could be regarded as a source of pollution that can cause environmental problems in the near shore areas. Three reference points (i.e. RP1, RP2 and RP3) are positioned downstream (i.e. east) of the source (river outlet) in order to determine the concentration levels at these points over the entire length of the simulation. RP1 and RP2 are located (side-by-side) at a distance of $200 \mathrm{~m}$ from the source, which is defined as a surface discharge. RP3 is situated $1.5 \mathrm{~km}$ downstream of the source and $200 \mathrm{~m}$ offshore. RP1 is positioned on the shore and RP2 is $200 \mathrm{~m}$ offshore north of $\mathrm{RP} 1$. The purpose of this arrangement is to compare the concentration levels along the shore with levels just off shore. A NW wind is applied to the bay under isothermal conditions for a period of 72 hours. A contaminant with a concentration of $10000 \mathrm{ppm}$ is released 24 hours after the simula- 

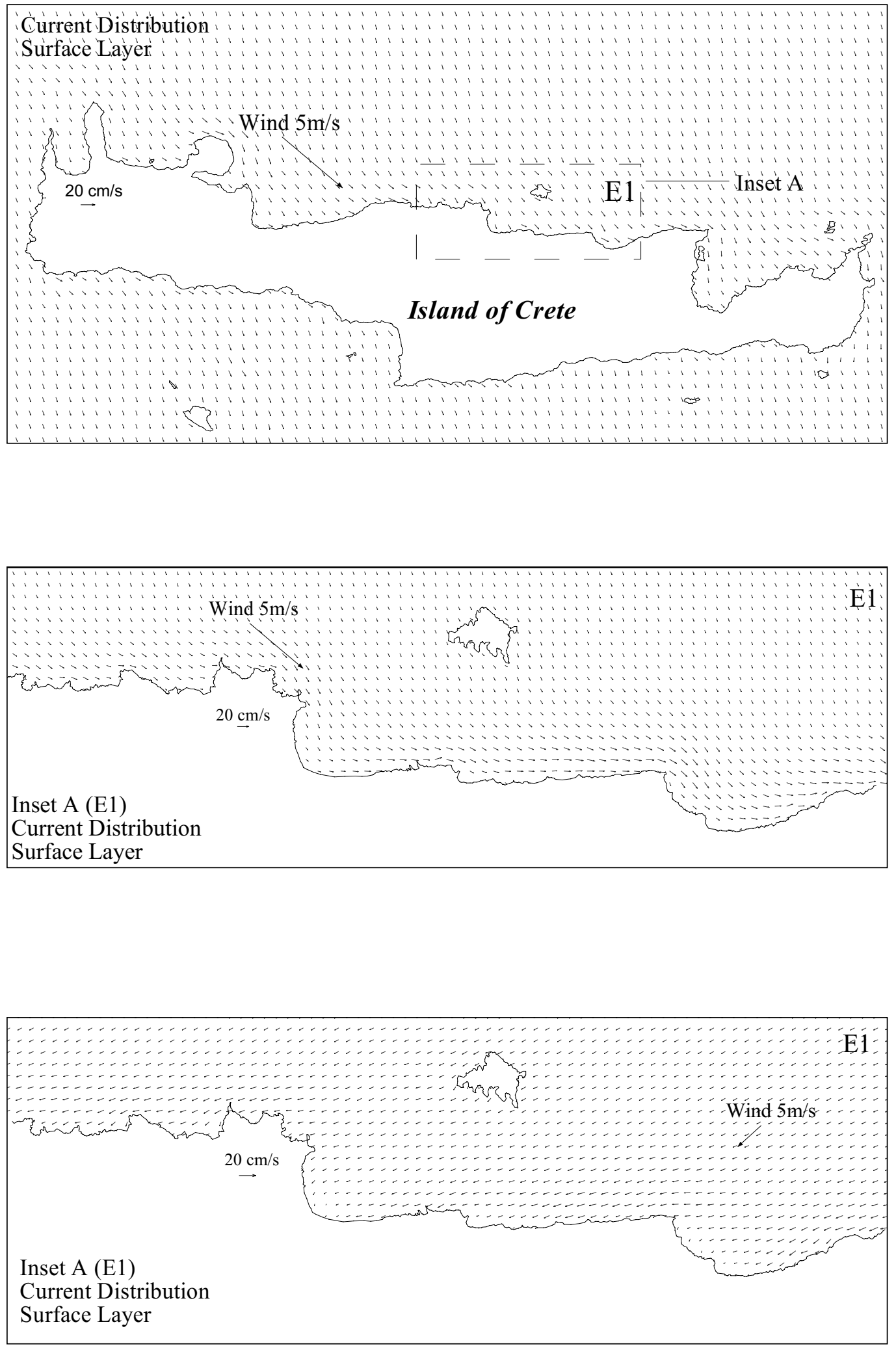

Figure 9. The surface layer current patterns around the Island of Crete (Section E) and a section (E1) of the northshore of Crete for a $5 \mathrm{~m} \mathrm{~s}^{-1} \mathrm{NW}$ wind. 

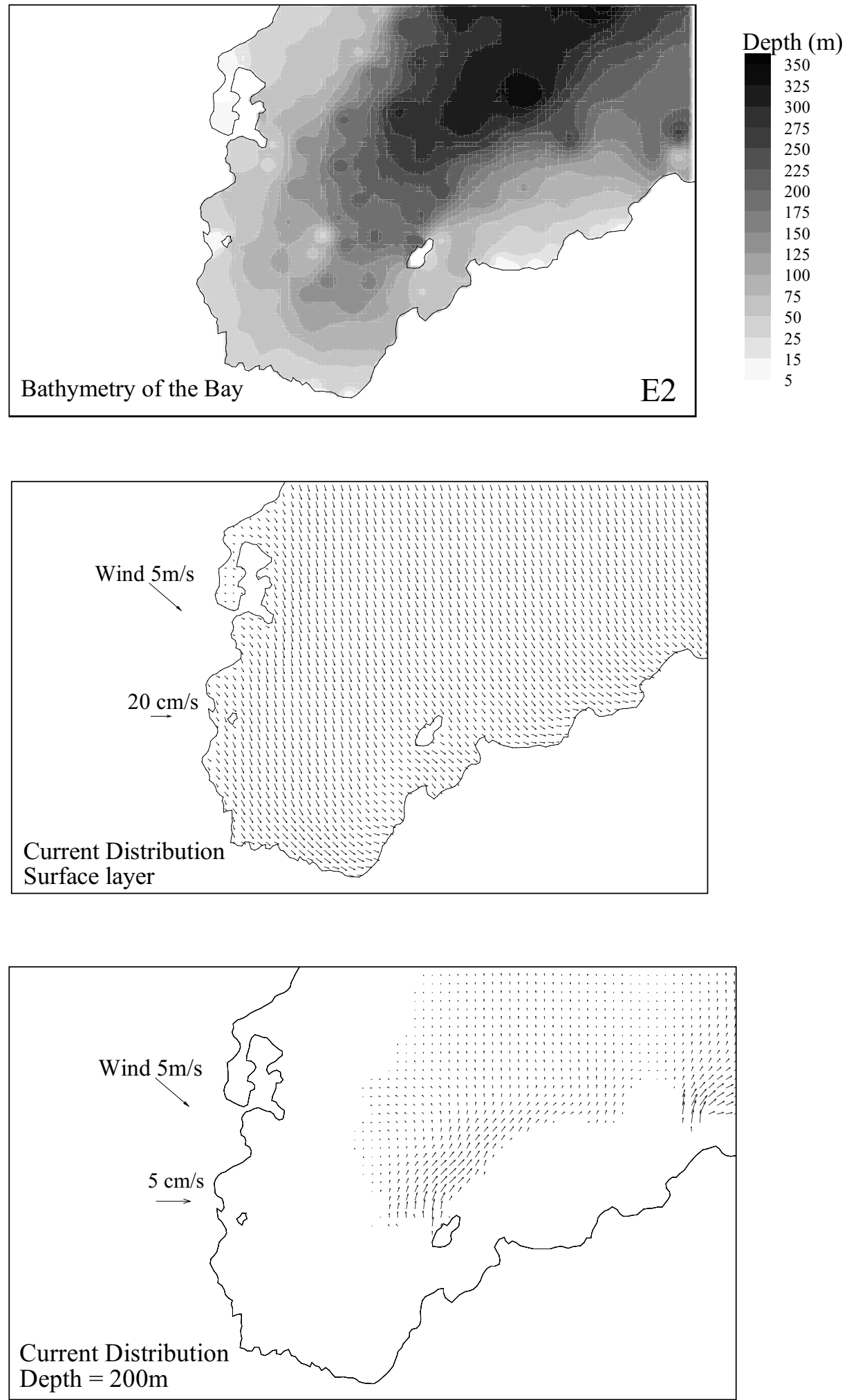

Figure 10. The bathymetry of Agios Nikolaos bay (Section E2) and the current patterns at the surface layer and at a depth of $200 \mathrm{~m}$ for a $5 \mathrm{~m} \mathrm{~s}^{-1} \mathrm{NW}$ wind. 


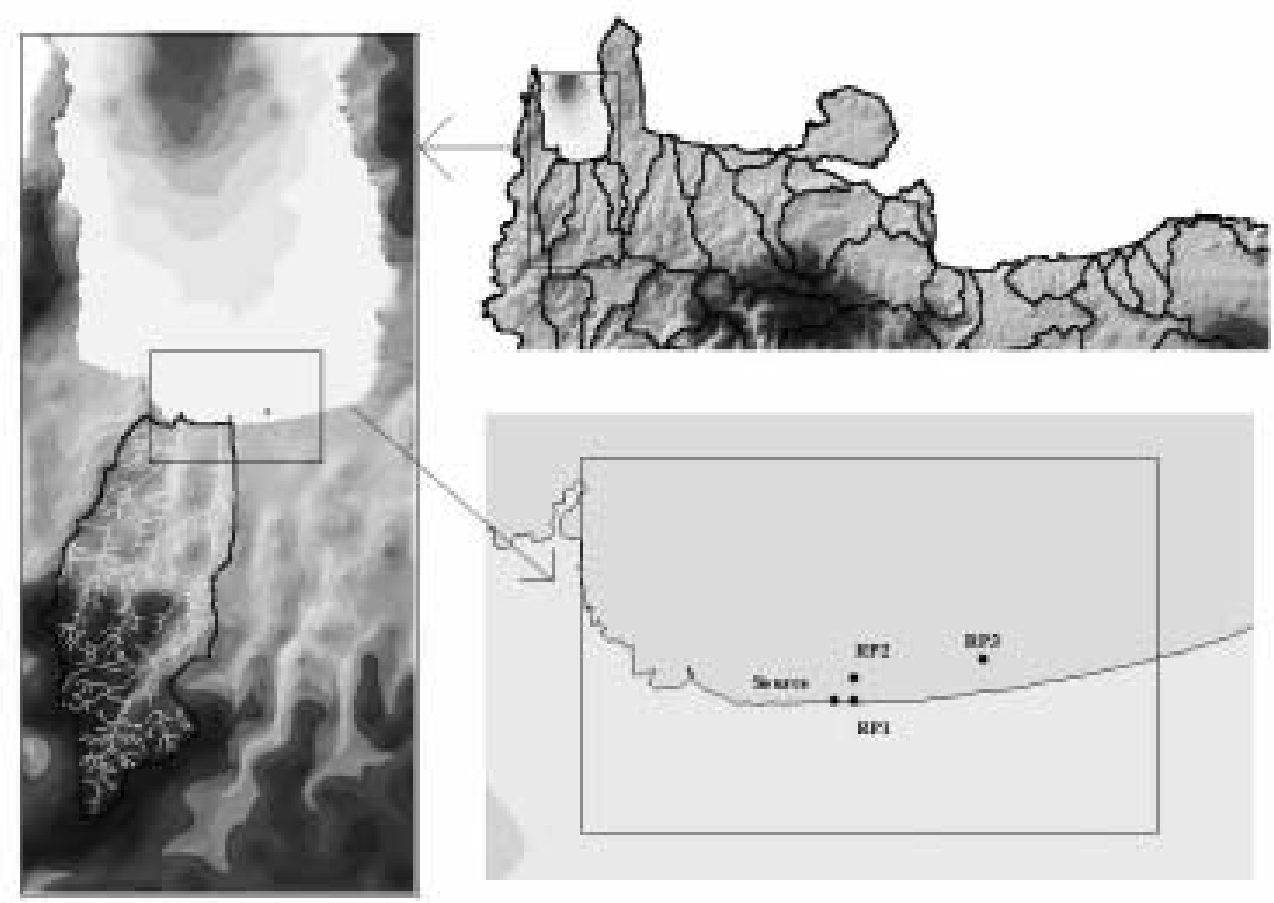

Figure 11. A watershed discharging to Kasteli bay through two streams

tion begins at a rate equal to $1 \mathrm{~m}^{3} \mathrm{~s}^{-1}$ over a fourhour period.

Figure 12 shows the movement of the plume 6,10 and 20 hours after the initial release of the pollutant. The plume is restricted in moving along the shoreline due to the currents generated by the NW wind. The contaminant is transported downstream as a plug flow and it takes approximately twenty hours (from the initial release of the pollutant) for the slug to pass over RP3, which is 1.5 $\mathrm{km}$ away from the source. A comparison of the depth-averaged time series concentration levels at the three reference points and the source is shown in Figure 13a. Based on the results, the pollutant exhibits a higher concentration at RP1 (i.e. along the shore) than at RP2, which is expected due to the location of the source and the alongshore currents. Figure $13 \mathrm{~b}$ shows the concentration time series at the source for various layers. The water depth at this point is approximately $5 \mathrm{~m}$. Under isothermal conditions the depth-averaged concentration is approximately $400 \mathrm{ppm}$; this suggests an initial dilution of 25:1.
The second scenario involves another bay in the region of Chania referred to as Chania bay (map section E3). Two cases will be used to examine the behavior of a contaminant discharged continuously into the bay from a submerged source at two different locations.

Case 1: corresponds to a source positioned $2 \mathrm{~km}$ offshore and approximately $900 \mathrm{~m} \mathrm{NW}$ of a small island. The depth of the source is $27 \mathrm{~m}$ (Figure 14).

Case 2: simulates the pollutant transport discharged from a source $10 \mathrm{~m}$ deep, situated $250 \mathrm{~m}$ offshore and $800 \mathrm{~m} \mathrm{SW}$ of the island (Figure 16). The purpose behind the two different orientations of the source is to analyze the movement of the contaminant with respect to the island. A NW wind of $5 \mathrm{~m} \mathrm{~s}^{-1}$ was applied to both cases in order to produce similar hydrodynamic conditions in the bay. The source released a pollutant with a concentration of $1000 \mathrm{ppm}$ at a rate of $1 \mathrm{~m}^{3} \mathrm{~s}^{-1}$. For both cases three reference locations are used (i.e. RP1, RP2 and RP3). RP1 is located between the mainland and the east side of the island. RP2 and 


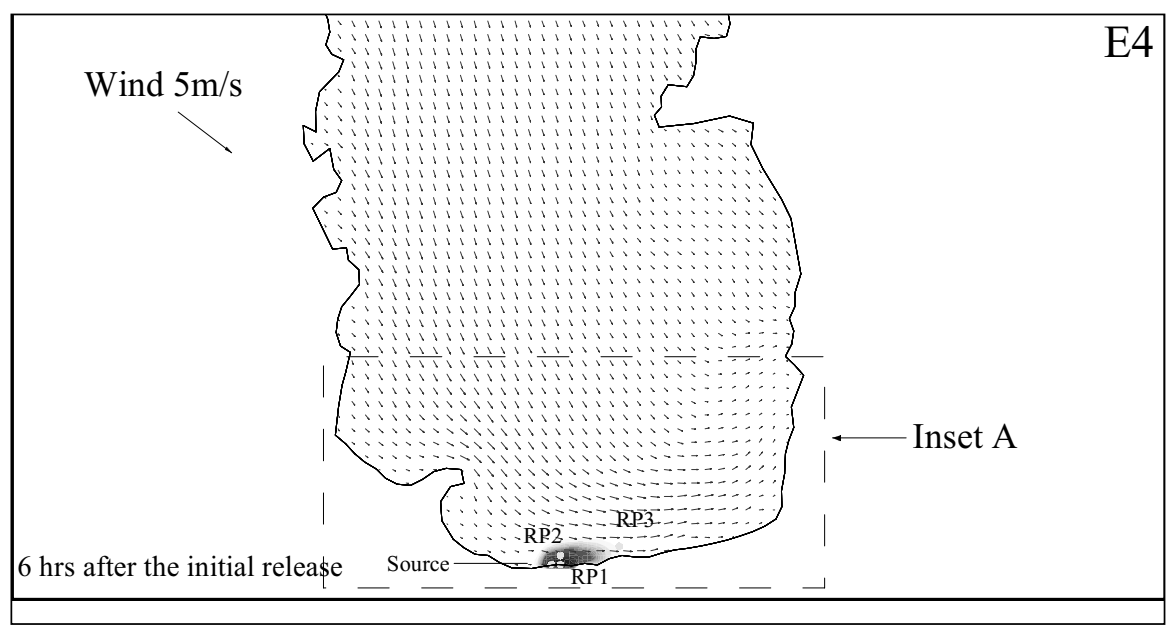

Conc. ppm
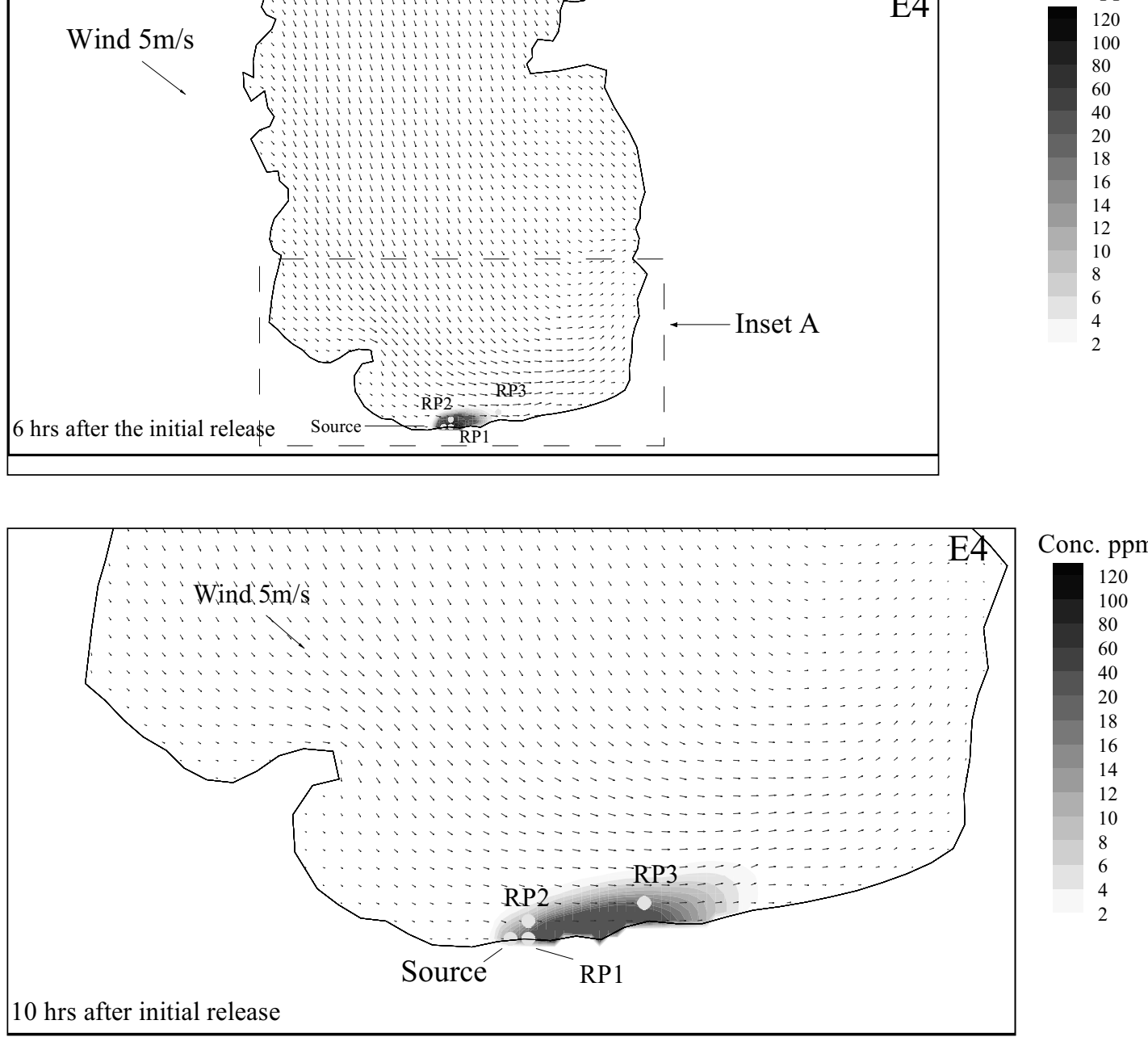

Conc. ppm

\begin{tabular}{l}
120 \\
100 \\
80 \\
60 \\
40 \\
20 \\
18 \\
16 \\
14 \\
12 \\
10 \\
8 \\
6 \\
4 \\
2 \\
\hline
\end{tabular}
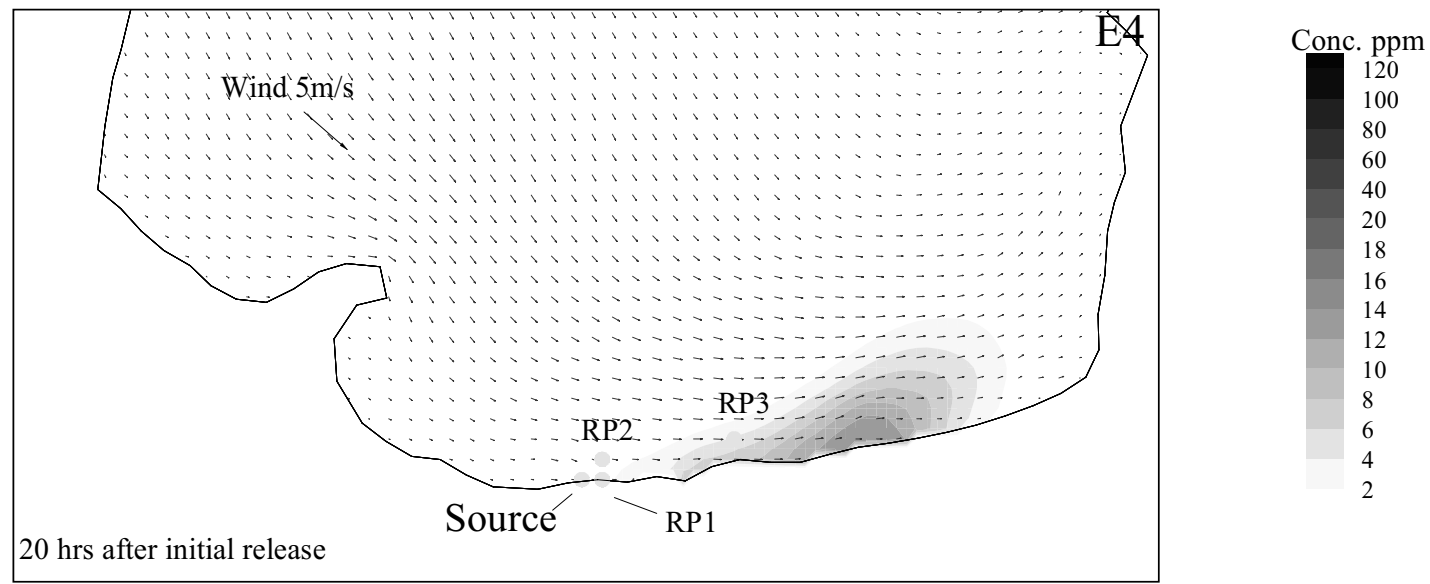

Figure 12. Current distribution and pollutant concentration contours at the surface layer of Kasteli bay under sea isothermal conditions and a $5 \mathrm{~ms}^{-1} \mathrm{NW}$ wind. 

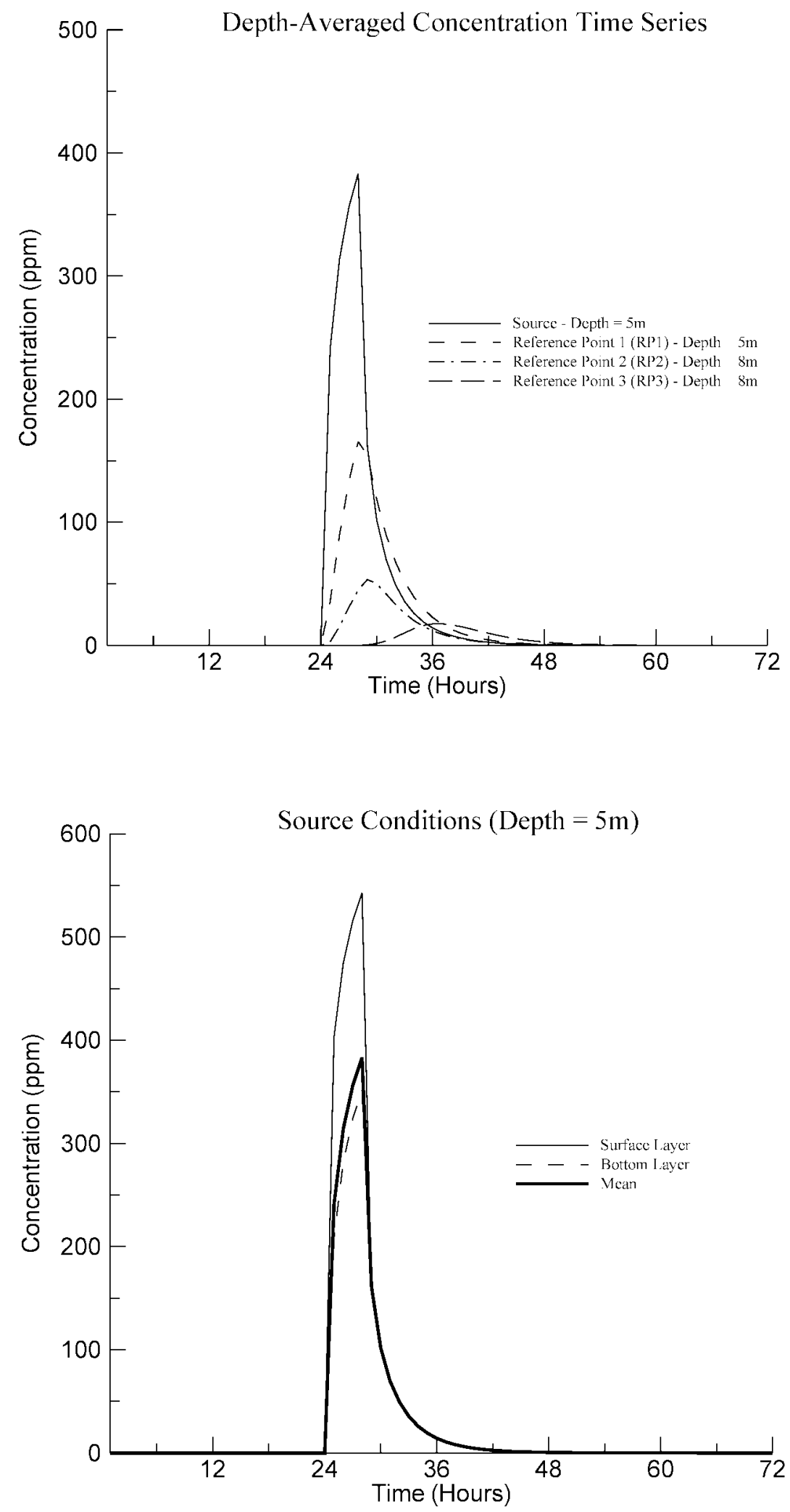

Figure 13. Concentration time series for a conservative pollutant released for a period of 4 hrs into Kasteli bay under sea isothermal conditions and a $5 \mathrm{~m} \mathrm{~s}^{-1} \mathrm{NW}$ wind. 

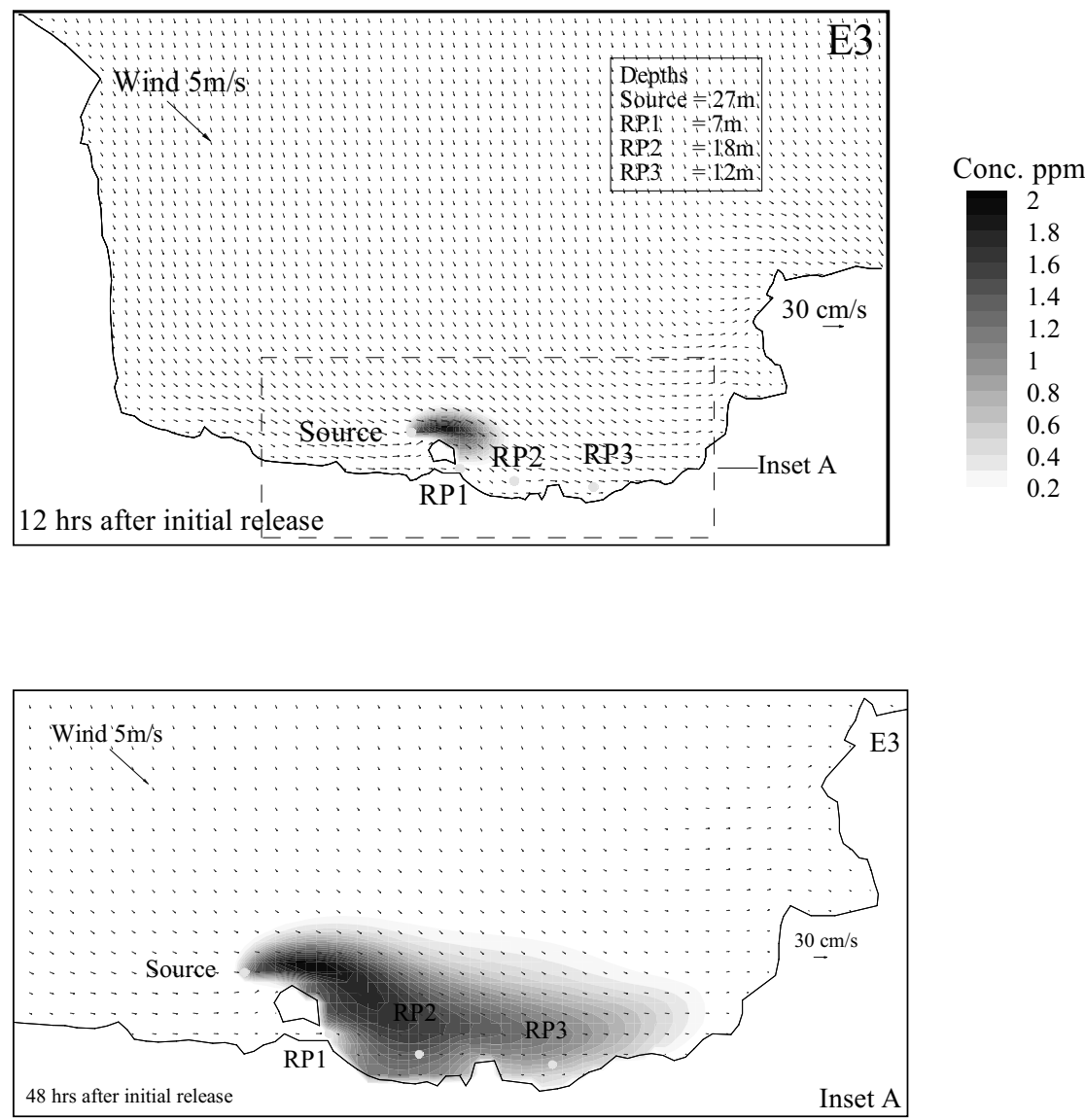

Figure 14. Case 1 - Current distribution and pollutant concentration contours at the surface layer for a continuous conservative pollutant released with a concentration of $1000 \mathrm{ppm}$ from a submerged source at a depth of $27 \mathrm{~m}$, in Chania bay under sea isothermal conditions and a $5 \mathrm{~m} \mathrm{~s}^{-1} \mathrm{NW}$ wind.

RP3 are defined further east, approximately 4 and 7 respectively from the source and $700 \mathrm{~m}$ offshore. Figure 14 describes the source and reference point locations as well as the movement of the pollutant 12 and 48 hours after the start of the simulation for Case 1. Due to the current patterns generated by the NW wind and the position of the source, the pollutant moves eastward around the north side of the island and then travels back towards the shore. Figure 15 shows the concentration time series at the source for Case 1 at different layers under isothermal conditions. The concentration is considerably higher at the bottom layer compared to the surface layer because temperature is not considered under isothermal conditions therefore more mixing occurs. A comparison of the depth-averaged con- centration time series for the three reference points is shown in Figure 15b. As expected the concentration at RP1 is lower than RP2 and RP3 due to its location. Based on the position of RP1 only the outer edge of the plume flows over this point, therefore levels will be much lower. Under isothermal conditions the concentration at RP2 and RP3 reach the same constant level (equal to $1.5 \mathrm{ppm}$ ) since RP3 although is further away from the source as compared with RP2 but is in lower depth of $12 \mathrm{~m}$ versus $18 \mathrm{~m}$. The plume movement for Case 2 is described in Figure 16 and suggests that a large amount of the contaminant will travel between the island and the mainland. In both cases the pollutant accumulates in the SE corner of the bay based on this particular NW wind pattern. 

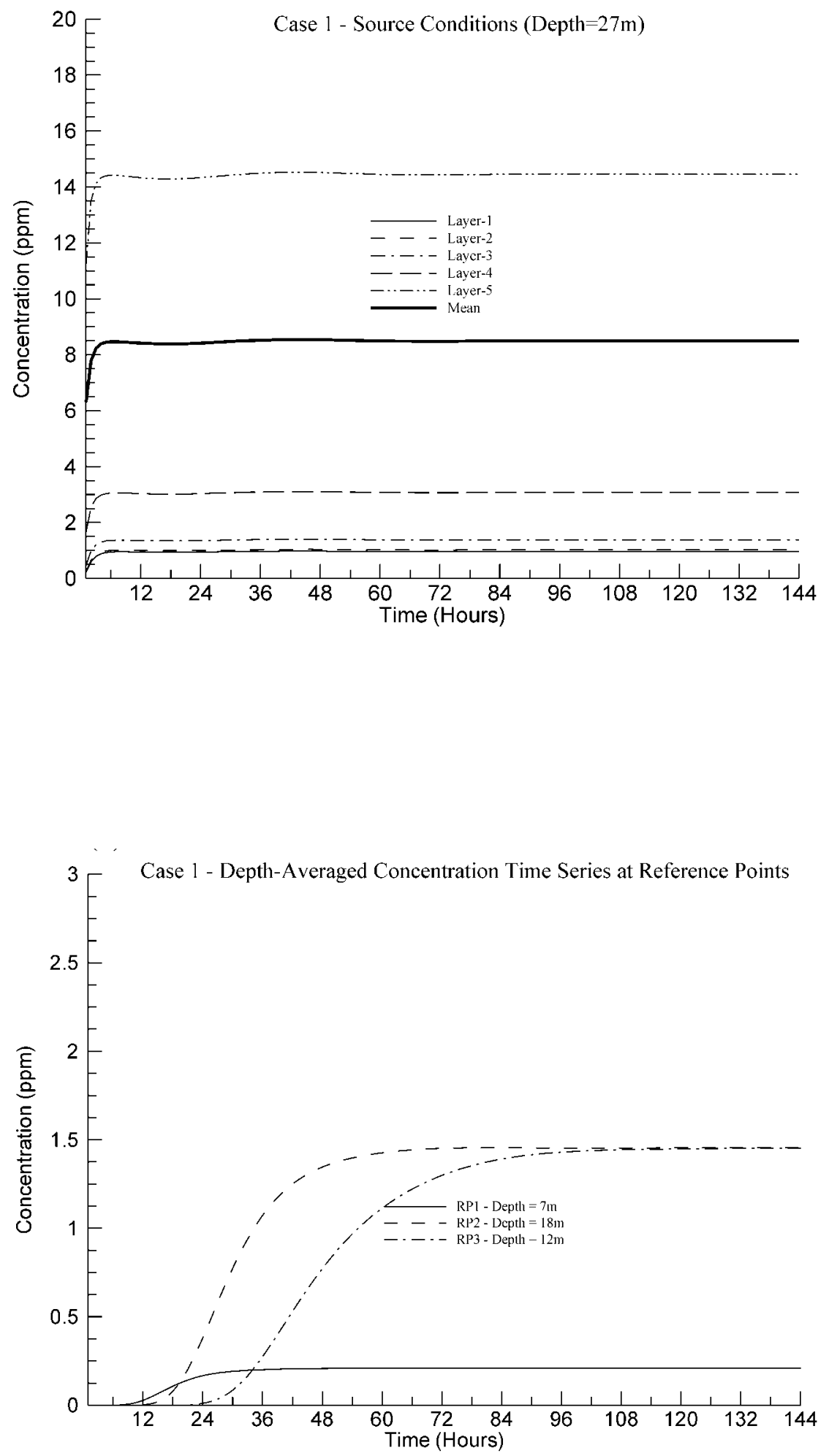

Figure 15. Case 1 - Concentration time series for a continuous conservative pollutant released with a concentration of 1000ppm into Chania bay under sea isothermal conditions and a $5 \mathrm{~m} \mathrm{~s}^{-1} \mathrm{NW}$ wind. 

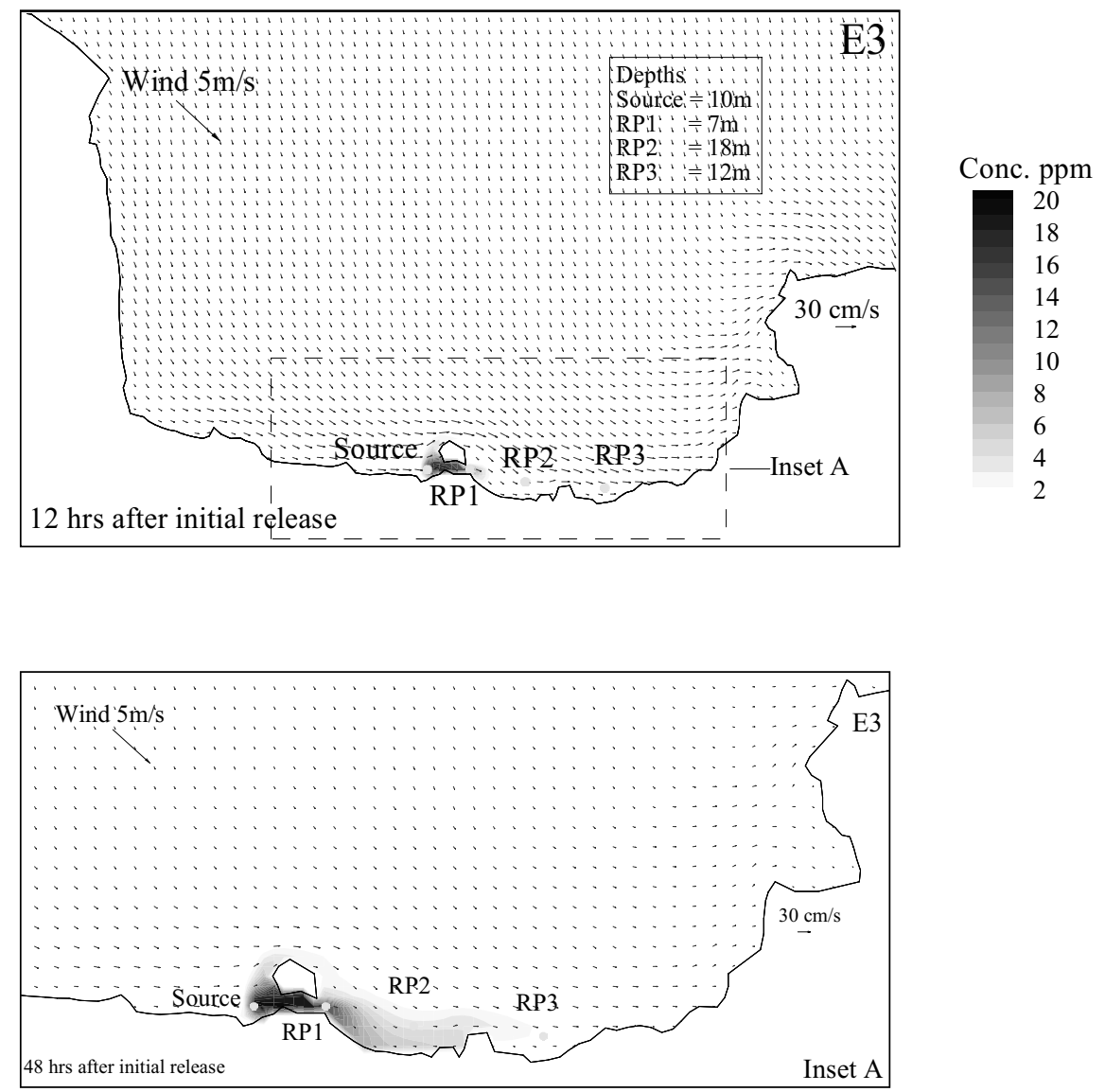

Figure 16. Case 2 - Current distribution and pollutant concentration contours at the surface layer for a continuous conservative pollutant released with a concentration of $1000 \mathrm{ppm}$ from a submerged source at a depth of $10 \mathrm{~m}$, in Chania bay under sea isothermal conditions and a $5 \mathrm{~m} \mathrm{~s}^{-1} \mathrm{NW}$ wind.

Figure 17 shows the concentration time series for the new source location (which is located at a depth of $10 \mathrm{~m}$ ) under both isothermal and stratified conditions for Case 2. The initial dilution is approximately 22:1 and 13:1, respectively. The dilution is less under stratified conditions due to the buoyant forces of the pollutant generated by temperature and density differences, which reduces the amount of mixing due to the contaminant moving quickly to the surface.

The behavior of the contaminant downstream of the source is analyzed by investigating the time series concentrations for the three reference points. Figure 18 shows the concentration levels for RP1, RP2 and RP3 over the entire length of the simulation under isothermal and stratified conditions for Case 2. Unlike Case 1 where the concentration at RP1 was quite low (see Figure $15 \mathrm{~b}$ ), due to the new source location RP1 records much higher concentration levels than RP2 and RP3. This makes sense since most of the pollutant now moves between the small island and the Island of Crete and directly over RP1.

\section{CONCLUSION}

The use of both the GIS and the 3D hydrodynamic/pollutant transport model, IDOR3D, proved to be an effective and flexible tool for analysis and research. The GIS module, in addition to saving time in generating input files, provides higher spatial accuracy since all themes are geographically referenced, eliminating the possibility of overlapping or misplacing. It also shows great flexibility in generating grids of different cell sizes, interpola- 

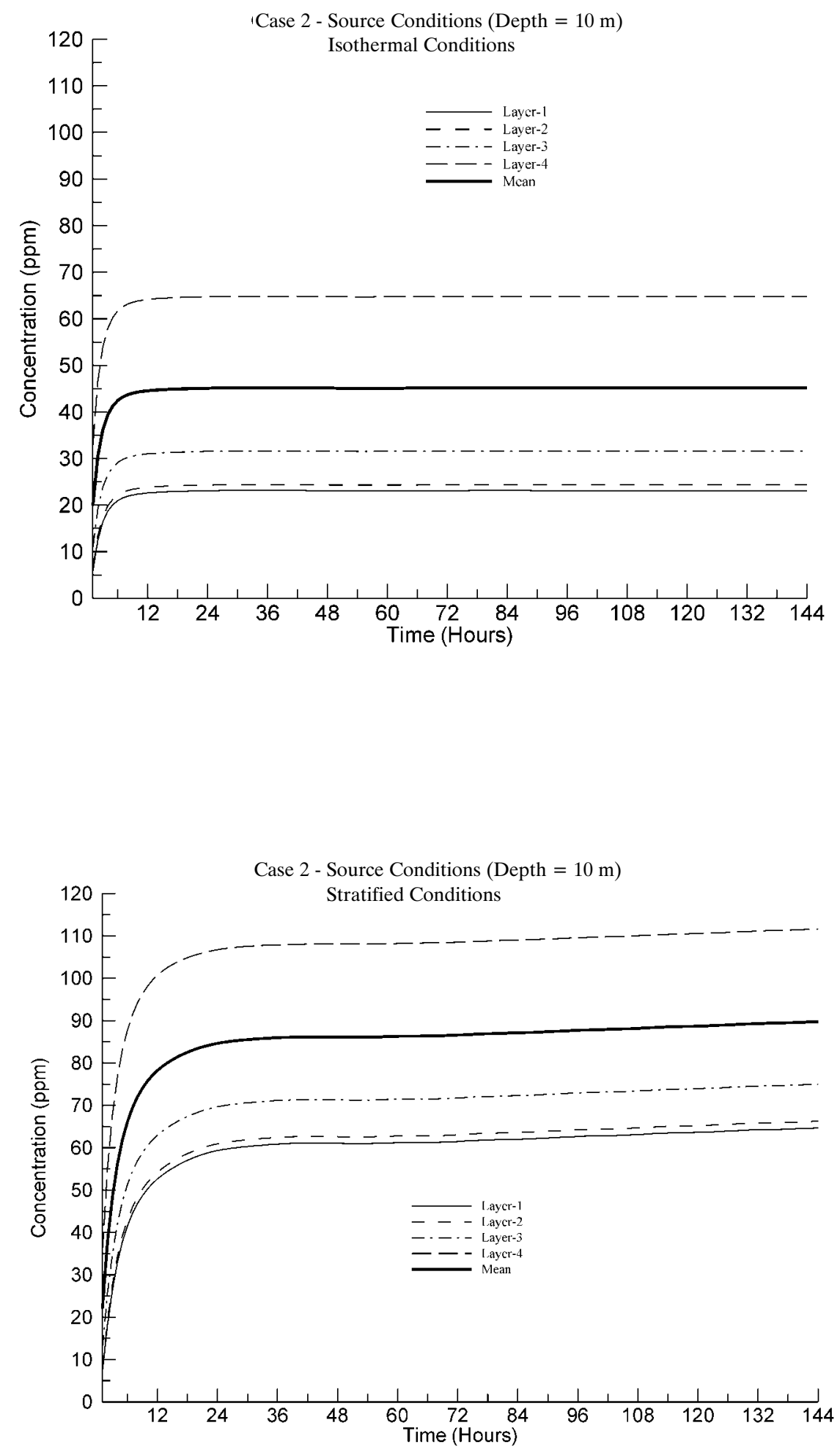

Figure 17. Case 2 - Concentration time series for a continuous conservative pollutant released with a concentration of 1000 ppm into Chania bay under a) isothermal and b) stratified conditions. 

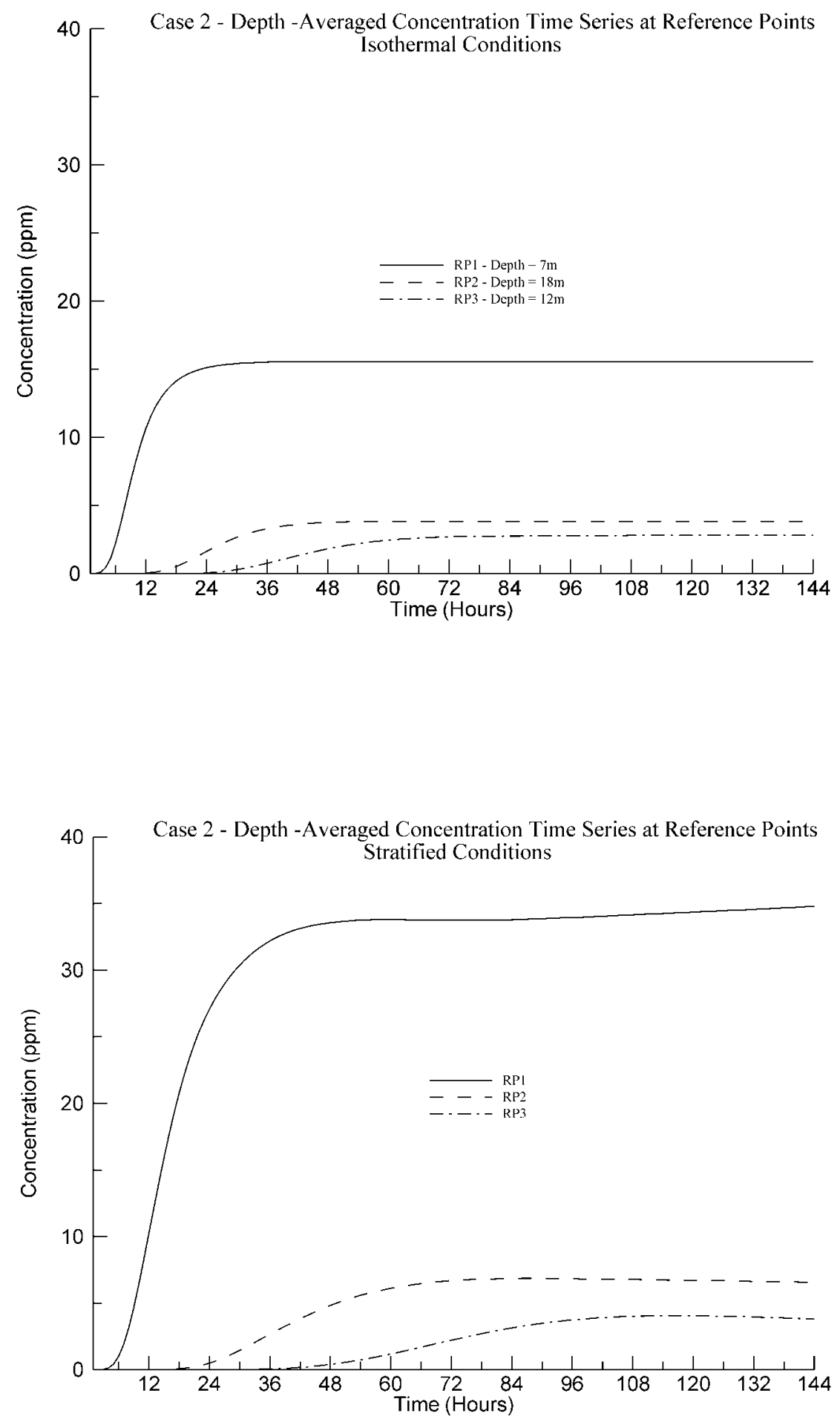

Figure 18. Case 2 - Depth-averaged concentration time series for a continuous conservative pollutant released with a concentration of 1000 ppm into Chania bay under a) isothermal and b) stratified conditions. 
tion techniques, and spatial extents. These elements are vital for research such as trial and repetition in sensitivity analysis cases.

The use of the module with IDOR3D was illustrated through multi-case scenarios involving a number of coastal areas in Greece. The different scenarios involved different: (a) grid sizes and bay sizes, (b) wind cases (magnitude and direction), (c) pollutant releases, and (d) open boundary conditions. The model with the input data from the GIS module performed efficiently. These findings are expected to contribute to improving the coastal engineering planning and management of the coastal areas in Greece.

\section{REFERENCES}

Arakawa, A. (1966), Computational design of long-term numerical integration of the equations of fluid motion. I. Two-dimensional incompressible flow, Journal of Computational Physics, 1, 119-143.

Boyle, S.J. and Tsanis, I.K., (1998), IDOR ${ }^{2 \mathrm{D}}$ GIS-A closely coupled Hydrodynamic/Pollutant Transport GIS model, $18^{\text {th }}$ Annual ESRI Int. User Conf., San Diego, California.

Boyle, S.J., Tsanis, I.K. and Kanaroglou, P.S. (1998), Developing geographic information systems for land use impact assessment in flooding conditions, Journal of Water Resources Planning and Management, ASCE, 124, 89-98.

Goodchild, M.F., Parks, B.O. and Steyaert, L.T. (1995), GIS and Environmental Modelling: Progress and Research Issues, GIS World Books.

Leendertse, J.J. and Liu, S.K. (1975), A three-dimensional model for estuaries and coastal seas. Aspects of Computation, Dept. of Interior, RAND, Santa Monica, 2, 1-29.

Lichy, C. (1998), A multidirectional and multifunctional gateway between GIS and hydrodynamic models, Hydroinformatics 98, Copenhagen, Denmark.

Maidment, D.R. (1993), GIS and Hydrologic Modelling. Environmental Modelling with GIS. Goodchild, M.F., Parks, B.O., and Steyaert, L.T. (eds.), Oxford University Press, New York, N.Y., pp. 147-167.

Naoum, S., Tsanis, I.K., and Fullarton, M. (2002), A GIS Pre-Processor For Pollutant Transport Modelling, Journal of Geographical and Environmental Modelling (to appear).

Naranjo, E., and Larsen, H., (1998), An integrated model to assess pollution loads with the use of GIS and numerical models, Hydroinformatics 98, Copenhagen, Denmark.

Patankar, S.V. (1980), Numerical heat transfer and fluid flow. Hemisphere, Washington D.C.

Pearce, B.R. and Cooper, C.K. (1981), Numerical circulation model for wind-induced flow, Journal of Hydraulic Engineering, ASCE, 107, 285-301.

Reid, R.O. (1957), Modification of the quadratic bottom-stress low of turbulent channel flow in the presence of surface wind-stress. Tech. Memor. No. 93, Beach Erosion Board, U.S. Dept. Army, Washington DC.

Roache, P.J. (1972), Computational fluid dynamics, Hermosa Publishers, Albuquerque, New Mexico.

Svensson, U. (1978), Mathematical model of the seasonal thermocline, Report No. 1002, Department of Water Resources Engineering, Univ. of Lund, Sweden

Tsanis, I.K. (1989), Simulation of wind-induced water currents, Journal of Hydraulic Engineering, ASCE, 115, 1113-1134.

Tsanis, I.K. (1996), Metropolitan Toronto Receiving Water Simulation Model, Protection and Restoration of the Environment III, Proceedings of an International Conference, Chania, Greece,0 48-56.

Tsanis, I.K. and Boyle, S. (2001), A 2D Hydrodynamic/Pollutant Transport GIS Model, Journal of Advances in Engineering Software, 32, 353-361.

Tsanis, I.K., Valeo, C., Wu, J., and Boyle, S. (1996), Managing contaminated sediments using a hydrodynamic model and a GIS, Environmental Technology, 17, 877-883. 